\title{
Feedback Systems on Extended Hilbert Space-Normality and Linearization
}

\author{
Messaoudi Khelifa \\ Correspondence: Messaoudi Khelifa, Faculty of MI, Department of Mathematics, University of Batna2 05000, Algeria
}

Received: January 27, 2020 Accepted: February 25, 2020 Online Published: March 6, 2020

doi:10.5539/jmr.v12n2p28 URL: https://doi.org/10.5539/jmr.v12n2p28

\begin{abstract}
The study of the normality of a feedback system on an extended Hilbert space has been made. The results of approximation of the solutions of such a nonlinear system by another linear are also established. This study represents an extension of the work of (Vaclav Dolezal, 1979), on a Hilbert space.
\end{abstract}

Keywords: feedback system, maximum monotone operator, extended Hilbert space, normality and linearization

AMS classification: 2000, 65J15; 65J10; 93A05; 47H07; 93B18

\section{Introduction}

In recent decades, special attention was devoted, to the study and the development of systems analysis, more precisely: electrical engineering, telecommunications and economic systems around the world. The fundamental publication of (G.Zames, 1963), has shown the important role of functional analysis in the study of nonlinear systems. (Vaclav Dolezal, 1979) introdced the feedback systems described by certain special types of operators, defined on appropriate spaces. He has established, a series of existence and uniqueness results, of the solutions of this system on a Hilbert space $H$. He obtained among others conditions of causality, stability and Lipschitz continuity. In addition, (Vaclav Dolezal, 1980; 1990) demonstrated, how these results are applicable, in several domains such that: control theory, network theory, solving the Hammerstein equation...etc. The techniques used by the author are based, on the surjectivity theorem, of the monotonic and coercive maximal operators of (R.T.Rockafellar, 1970). Since, the resolution of some special cases of feedback systems, on normed spaces, is often a difficult task, (Vaclav Dolezal, 1979) introduced, the notion of extended Hilbert space $H e$, and obtained, a normality result for a feedback system, on this space. Morover, (Vaclav Dolezal, 1991), showed how to use such a space, in the study of stability robustness, and the sensitivity of this system. In the present work, we propose to formalize and generalize in $\mathrm{He}$, the results obtained in $H$. One of our fundamental results is that, the behavior of $\left[A_{1}, A_{2}\right]$ is completely determined, by the inverse of some application $M_{a}=I+A_{2}\left(a+A_{1}\right)$ (see (2)). Note that, in the case where the operators $A_{1}$ and $A_{2}$ are not linear, and if $\left(u_{1}, u_{2}\right) \mapsto\left(e_{1}, e_{2}\right)$, then $\left(e_{1}, e_{2}\right)=\left(M_{u_{2}}^{-1} u_{1}, u_{2}+A_{1} M_{u_{2}}^{-1} u_{1}\right)$. If one of the two operators is linear, the writing of the solution $\left(e_{1}, e_{2}\right)$, can take forms, that do not necessarily depend, on the inverse of the operator $M_{u_{2}}$, (section 4, (4)\&(5)). These forms, play an important role in the study of the sensitivity (Vaclav Dolezal, 1990), and give suitable estimates of the solutions in the sense of section 3.2. For more details, on the study of the inverse of such an operator, which is non linear, one consult (Vaclav Dolezal, 1998; 1999; 2003). It is then natural, to proceed to the approximation method. Therefore, to find an approximate solution of $\left[A_{1}, A_{2}\right]$, supposed nonlinear, by one linearizes, in the neighborhood of zero. We then consider, a linear $\left[A_{1}^{0}, A_{2}^{0}\right]$ on $\mathrm{He}$, and prove that, if $\left(u_{1}, u_{2}\right) \mapsto\left(e_{1}, e_{2}\right) \in H_{e}^{2}$ and $\left(u_{1}, u_{2}\right) \mapsto\left(e_{1}^{0} e_{2}^{0}\right) \in H_{e}^{2}$, where $\left(u_{1}, u_{2}\right) \in H_{P}^{2}$, with $\left\|u_{1}\right\| \leq r,\left\|u_{2}\right\| \leq r(r>0)$ and $\left(e_{1}, e_{2}\right),\left(e_{1}^{0} e_{2}^{0}\right)$ the respective solutions of $\left[A_{1}, A_{2}\right]$ and $\left[A_{1}^{0}, A_{2}^{0}\right]$. There exists, $k_{11}, k_{12}, k_{21}, k_{22}$, positive real constants such that

$$
\left\|e_{1}-e_{1}^{0}\right\| \leq k_{11}\left\|u_{1}\right\|+k_{12}\left\|u_{2}\right\|
$$

and

$$
\left\|e_{2}-e_{2}^{0}\right\| \leq k_{21}\left\|u_{1}\right\|+k_{22}\left\|u_{2}\right\|
$$

Our work is organized as follows: in section 2, we recall some definitions concerning, the existence and uniqueness of solutions of feedback systems on a vector space, the definitions of an extended Hilbert space, the spaces $\mathcal{M}$ and Lip. Section 3 is reserved for our results of, normality and linearization of nonlinear feedback systems on $H_{e}$. Section 4 contains the reminders of the results used in this paper. 


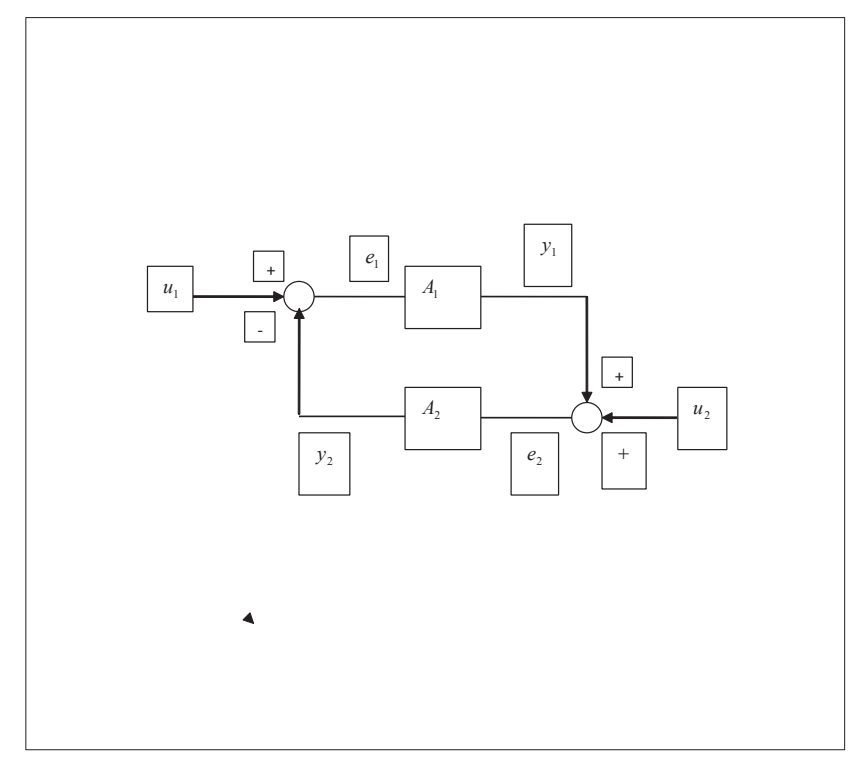

\section{Definitions and Notations}

Let $H$ be a real vector space, $2^{H}$ the set of parts of $H, A$ an application of $H$ into $2^{H}$ and $D(A)=\{x \in H ; A x \neq \emptyset\}$, the domain of $A$. We say that, $A$ is an operator, if $D(A)=H$ and $A x$ is a singleton for all $x$ in $H$.

\section{Definition 2.1.}

(a) We call feedback system on $H$, and we write $F S$, any pair $\left[A_{1}, A_{2}\right]$ of applications of $H$ in $2^{H}$.

(b) We say that, an element $\left(e_{1}, e_{2}\right)$ (error) of $H^{2}$ is a solution of $\left[A_{1}, A_{2}\right]$, corresponding to the given $\left(u_{1}, u_{2}\right)$ (input) of $H^{2}$ and we write $\left(u_{1}, u_{2}\right) \mapsto\left(e_{1}, e_{2}\right)$, if there exists $\left(y_{1}, y_{2}\right)$ (output) in $A_{1} e_{1} \times A_{2} e_{2}$ such that:

$$
\left\{\begin{array}{l}
e_{1}=u_{1}-y_{2} \\
e_{2}=u_{2}+y_{1}
\end{array}\right.
$$

The meaning of the preceding notions, can be understood for exemple, from a physical point of view, by looking at the above representative schema

Definition 2.2. We say that the $F S\left[A_{1}, A_{2}\right]$ on $H$ is:

(i) Resoluble, if for all $\left(u_{1}, u_{2}\right) \in H^{2}$, there exists a solution $\left(e_{1}, e_{2}\right) \in H^{2}$, corresponding to $\left(u_{1}, u_{2}\right)$.

(ii) Unambiguous, if each solution is unique.

(iii) Normal, if it is resoluble and unambiguous.

The existence and uniqueness results of the solutions of $\left[A_{1}, A_{2}\right]$ over $H$, are based on the mapping $M_{a}: H \mapsto 2^{H}$ defined for all $(a, x) \in H^{2}$, by

$$
M_{a} x=x+A_{2}\left(a+A_{1} x\right)
$$

Let $H$ be a Hilbert space, $<,>$ the scalar product over $H$, $\|$.$\| the norm induced by the scalar product, H_{e}$ a vector space containing $H$, and $\mathcal{P}=\left\{P_{\alpha} ; \alpha \in I\right\}$ a non-empty family of linear operators on $H_{e}$. For all $P \in \mathcal{P}, x^{(P)}$ will denote an element of $H_{P}:=P H$.

Definition 2.3. We say that, $H_{e}$ is an extended Hilbert, or an extension of $H$, if the following axioms are verified:

(i) $P^{2}=P, \forall P \in \mathcal{P}$.

(ii) $\left(P_{1} P_{2}=P_{2} P_{1}\right.$ and $\left.P_{1} P_{2} \in \mathcal{P}\right), \forall P_{1}, P_{2} \in \mathcal{P}$.

(iii) If $x \in H_{e}$, then $P x \in H, \forall P \in \mathcal{P}$. 
(iv) If $\forall P \in \mathcal{P}$, the element $x^{(P)}$ is in $H_{P}$, and $P_{0} x^{\left(P_{1}\right)}=P_{0} x^{\left(P_{2}\right)} \forall P_{1}, P_{2} \in \mathcal{P}$, where $P_{0}=P_{1} P_{2}$. Then, there exists $x$ in $H_{e}$, such that $x^{(P)}=P x, \forall P \in \mathcal{P}$.

(v) If $x \in H$, then $\|P x\| \leq\|x\|, \forall P \in \mathcal{P}$.

(vi) If $x \in H_{e}$ and $\|P x\| \leq a, \forall P \in \mathcal{P}$, where $a \geq 0$. Then $x \in H$ and $\|x\| \leq a$.

It is straightforward to cheque that:

(a) $\forall P_{1}, P_{2} \in \mathcal{P}, P_{0} P_{1}=P_{0} P_{2}=P_{0}$, where $P_{0}=P_{1} P_{2}$.

(b) $\forall P \in \mathcal{P}, P H_{e}=H_{P}$, and $H_{P}$ is a closed subspace of $H$.

(c) If $x \in H_{e}$ and $P x=0$ for all $P \in \mathcal{P}$, then $x=0$.

(d) The element $x \in H$, in axiom (iv) is unique.

(e) $\langle P x, y\rangle=\langle x, P y\rangle$, for every $x, y \in H$ and every $P \in \mathcal{P}$.

Exemple2.1. Let $\mathbb{R}$ be the set of real numbers, $\mathbb{R}^{n}\left(n \in \mathbb{N}^{*}\right), n$ times the product of $\mathbb{R}$, and $\bar{C}\left(\mathbb{R}_{+} ; \mathbb{R}^{n}\right)$ the vector space of the continuous functions $x: \mathbb{R}_{+} \rightarrow \mathbb{R}^{n} . C\left(\mathbb{R}_{+} ; \mathbb{R}^{n}\right)$ denotes the subspace of the functions of $\bar{C}\left(\mathbb{R}_{+} ; \mathbb{R}^{n}\right)$, which are bounded, for the norm defined by: for all $x \in C\left(\mathbb{R}_{+} ; \mathbb{R}^{n}\right),\|x\|=\sup \left\{|x(t)| ; t \in \mathbb{R}_{+}\right\}$where $|$.$| is a norm of \mathbb{R}^{n}$.

For the family $\mathcal{P}=\left\{P_{\alpha}: \bar{C}\left(\mathbb{R}_{+} ; \mathbb{R}^{n}\right) \rightarrow C\left(\mathbb{R}_{+} ; \mathbb{R}^{n}\right) ; \alpha \in \mathbb{R}_{+}\right\}$where, for all $\alpha \in \mathbb{R}_{+}$

$$
\left(P_{\alpha} x\right)(t)=\{. x(t) \text { if } t \in[0, \alpha[; x(\alpha) \text { if } t \in[\alpha,+\infty[,
$$

$\bar{C}\left(\mathbb{R}_{+} ; \mathbb{R}^{n}\right)$ is an extended space of $C\left(\mathbb{R}_{+} ; \mathbb{R}^{n}\right)$.

Exemple2.2. Let $\overline{L_{2}}\left(\mathbb{R}_{+}\right)$be the space of the functions $t \in \mathbb{R}_{+} \longmapsto x(t) \in \mathbb{R}$, which are locally square integrable on $\mathbb{R}_{+}$, and $L_{2}\left(\mathbb{R}_{+}\right)$the subspace of the functions $x$, which are square integrable on $\mathbb{R}_{+}$.

We define the family $\mathcal{P}=\left\{P_{\alpha}: \overline{L_{2}}\left(\mathbb{R}_{+}\right) \rightarrow L_{2}\left(\mathbb{R}_{+}\right) ; \alpha \in \mathbb{R}_{+}\right\}$by:

$$
\left(P_{\alpha} x\right)(t)=\{. x(t) \text { if } t \in[0, \alpha] ; 0 \text { if } t \in] \alpha,+\infty[.
$$

for all $\alpha \in \mathbb{R}_{+} . \overline{L_{2}}\left(\mathbb{R}_{+}\right)$is an extended space of $L_{2}\left(\mathbb{R}_{+}\right)$.

Definition 2.4. An operator $A: H_{e} \rightarrow H_{e}$ is called causal if, $\forall P \in \mathcal{P}, P A=P A P$.

Definition 2.5. An normal $F S\left[A_{1}, A_{2}\right]$ on $H_{e}$, is called causal if, for $\left(u_{1}, u_{2}\right) \mapsto\left(e_{1}, e_{2}\right)$ and $\left(u_{1}^{\prime}, u_{2}^{\prime}\right) \mapsto\left(e_{1}^{\prime}, e_{2}^{\prime}\right)$, such that $\forall P \in \mathcal{P}, P u_{1}=P u_{1}^{\prime}$ and $P u_{2}=P u_{2}^{\prime}$, then $P e_{1}=P e_{1}^{\prime}$ and $P e_{2}=P e_{2}^{\prime}$.

Definition 2.6. We say that, an operator $A: H \rightarrow H$ is hemicontinuous in $x_{0} \in H$, if for all $\omega \in H$ and for any real sequence $t_{n} \rightarrow 0$; the sequence $A\left(x_{0}+t_{n} \omega\right)$ converges weakly to $A\left(x_{0}\right)$ in $H$. $A$ is hemicontinuous on $H$, if it is hemicontinuous in any point of $H$.

Before stating the results of normalities, we introduce the two following spaces:

$$
\mathcal{M}=\left\{N: H \rightarrow H \text { such that } \mu_{N}:=\inf _{\substack{x_{1}, x_{2} \in H \\ x_{1} \neq x_{2}}} \frac{\left\langle N x_{1}-N x_{2}, x_{1}-x_{2}\right\rangle}{\left\|x_{1}-x_{2}\right\|^{2}}>-\infty\right\}
$$

and

$$
\text { Lip }=\left\{N: H \rightarrow H \text { such that }\|N\|^{*}:=\sup _{\substack{x_{1}, x_{2} \in H \\ x_{1} \neq x_{2}}} \frac{\left\|N x_{1}-N x_{2}\right\|}{\left\|x_{1}-x_{2}\right\|}<+\infty\right\}
$$

It is clear that Lipis $\subset \mathcal{M}$ and $\forall M, N \in \mathcal{M}, \forall \alpha \geq 0$

(i) $M+N, \alpha N \in \mathcal{M}, \mu_{M+N} \geq \mu_{M}+\mu_{N}$ and $\mu_{\alpha N}=\alpha \mu_{N}$. 
(ii) $N$ is monotone (respectively strictly monotone) iff $\mu_{N} \geq 0$ (respectively $\mu_{N}>0$ ).

On the other hand, $\forall M, N \in$ Lip $, \forall \alpha, \beta \in \mathbb{R}$

(iii) $\|N\|^{*} \geq\left|\mu_{N}\right|,\|N\|^{*} \geq 0$ and $\|N\|^{*}=0$ iff $N$ is constant.

(iv) $\alpha N+\beta M, N M \in$ Lip, $\|\alpha N\|^{*}=|\alpha|\|N\|^{*},\|N+M\|^{*} \leq\|N\|^{*}+\|M\|^{*}$ and $\|N M\|^{*} \leq\|N\|^{*}\|M\|^{*}$.

(v) If $N$ is linear, then $N$ is bounded iff $N \in \operatorname{Lip}$, in this case $\|N\|^{*}=\|N\|$.

\section{Fundamental Results}

This section is divided into two subsections. In the first one, we give and prove two normality results. In the second, we have formalize and obtained linearization results.

\subsection{Normality of the Feedback System on $H_{e}$}

The first result of normality in this work is:

Theorem 3.1. Let $A_{1}, A_{2}: H_{e} \rightarrow H_{e}$ be two causal operators, whose $A_{2}$ is linear, and for all $P \in \mathcal{P}, A_{1 P}$ and $A_{2 P}$ the respective restrictions of $P A_{1}$ and $P A_{2}$ to $H_{P}$. We assumed that for any $P \in \mathcal{P}$

(i) $A_{1 P} \in \mathcal{M}, A_{1 P}$ is hemicontinuous and $\mu_{A_{1 P}} \leq 0$.

(ii) $A_{2 P} \in \mathcal{M}$, and $\mu_{A_{2 P}}>0$.

(iii) $\mu_{A_{2 P}}+\mu_{A_{1 P}}\left\|A_{2 P}\right\|^{2}>0$.

Then, the $F S\left[A_{1}, A_{2}\right]$ on $H_{e}$ is normal and causal.

If $\left\|A_{2 P}\right\| \leq k,\left(\mu_{A_{2 P}}+\mu_{A_{1 P}}\left\|A_{2 P}\right\|^{2}\right)^{-1} \leq \lambda ;\left(u_{1}, u_{2}\right) \mapsto\left(e_{1}, e_{2}\right) \in H_{e}^{2}$ and $\left(u_{1}^{\prime} u_{2}^{\prime}\right) \mapsto\left(e_{1}^{\prime}, e_{2}^{\prime}\right) \in H_{e}^{2}$, with $\left(u_{1-} u_{1}^{\prime}, u_{2-} u_{2}^{\prime}\right) \in H^{2}$ then $\left(e_{1-} e_{1}^{\prime}, e_{2-} e_{2}^{\prime}\right) \in H^{2}$ and

$$
\left\|e_{1-} e_{1}^{\prime}\right\| \leq \lambda k\left\|u_{1-} u_{1}^{\prime}\right\|+\lambda k^{2}\left\|u_{2-} u_{2}^{\prime}\right\| .
$$

If in addition, $A_{1 P} \in$ Lip and $\left\|A_{1 P}\right\|^{*} \leq k^{*}$, then

$$
\left\|e_{2-} e_{2}^{\prime}\right\| \leq \lambda k k^{*}\left\|u_{1-} u_{1}^{\prime}\right\|+\left(1+\lambda k^{*} k^{2}\right)\left\|u_{2-} u_{2}^{\prime}\right\|,
$$

where $\lambda, k$ and $k^{*}$ are positive real constants.

Proof. Let for all $P \in \mathcal{P}, N_{P}=I+A_{2 P} A_{1 P}$. The operator $N_{P}$ satisfies the conditions of lemma 4.3, so it is invertible, the inverse $N_{P}^{-1} \in \operatorname{Lip}$ and $\left\|N_{P}^{-1}\right\|^{*} \leq\left\|A_{2 P}\right\|\left(\mu_{A_{2 P}}+\mu_{A_{1 P}}\left\|A_{2 P}\right\|^{2}\right)^{-1}$. Moreover $N_{P}$ is the restriction to $H_{P}$ of the operator $P N$, with $N=I+A_{2} A_{1}$ and it is causal. Indeed, since for all $P \in \mathcal{P}, P\left[P\left(I+A_{2} A_{1}\right)-\left(I+P A_{2} A_{1}\right)\right]=0$, then $P N=$ $P\left(I+A_{2} A_{1}\right)=I+P A_{2} A_{1}$ (see (c) in section 2). So, for all $P \in \mathcal{P}, P N=I+P A_{2} P A_{1}=I+A_{2 P} A_{1 P}=N_{P}$ and

$$
\begin{aligned}
P N_{P} P & =P\left(I+A_{2 P} A_{1 P}\right) P=P\left(P+A_{2 P} A_{1 P} P\right)=P\left(P+P A_{2} P A_{1} P\right) \\
& =P\left(P+P^{2} A_{2} P A_{1}\right)=P^{2}\left(I+P A_{2} P A_{1}\right)=P\left(I+A_{2 P} A_{1 p}\right)=P N_{P} .
\end{aligned}
$$

We deduce (cf lemma 4.3, lemma 4.6), that the operators $N, N_{P}^{-1}$ are invertible and causal. According to corollary 4.2 and (4) the $F S\left[A_{1}, A_{2}\right]$ is normal,

$$
\left(e_{1}, e_{2}\right)=\left(\left(I+A_{2} A_{1}\right)^{-1}\left(u_{1}-A_{2} u_{2}\right), u_{2}+A_{1}\left(I+A_{2} A_{1}\right)^{-1}\left(u_{1}-A_{2} u_{2}\right)\right)
$$

therefore

$$
\left(P e_{1}, P e_{1}^{\prime}\right)=\left(N_{P}^{-1}\left(P u_{1}-A_{2 P} u_{2}\right), N_{P}^{-1}\left(P u_{1}^{\prime}-A_{2 P} u_{2}^{\prime}\right)\right)
$$

and

$$
\begin{aligned}
\left\|P\left(e_{1-} e_{1}^{\prime}\right)\right\| & =\left\|N_{P}^{-1}\left(P u_{1}-A_{2 P} u_{2}\right)-N_{P}^{-1}\left(P u_{1}^{\prime}-A_{2 P} u_{2}^{\prime}\right)\right\| \\
& \leq\left\|N_{P}^{-1}\right\|^{*}\left\|\left(P u_{1}-A_{2 P} u_{2}\right)-\left(P u_{1}^{\prime}-A_{2 P} u_{2}^{\prime}\right)\right\| \\
& \leq k \lambda\left(\left\|P\left(u_{1}-u_{1}^{\prime}\right)\right\|+\left\|A_{2 P}\left(u_{2}-u_{2}^{\prime}\right)\right\|\right) \\
& \leq k \lambda\left(\left\|u_{1}-u_{1}^{\prime}\right\|+\left\|A_{2 P}\right\|\left\|u_{2}-u_{2}^{\prime}\right\|\right) \\
& \leq k \lambda\left\|u_{1}-u_{1}^{\prime}\right\|+\lambda k^{2}\left\|u_{2}-u_{2}^{\prime}\right\|
\end{aligned}
$$


where the axiom ( $v)$ was used.

According to the axiom (vi), $e_{1-} e_{1}^{\prime} \in H$ and

$$
\left\|e_{1-} e_{1}^{\prime}\right\| \leq \lambda k\left\|u_{1}-u_{1}^{\prime}\right\|+\lambda k^{2}\left\|u_{2}-u_{2}^{\prime}\right\| .
$$

If now $P u_{1}=P u_{1}^{\prime}$ and $P u_{2}=P u_{2}^{\prime}$, the causality of $A_{2}$ and the first inequality above leads to $P e_{1}=P e_{1}^{\prime}$,. According to (1) $e_{2}=A_{1} e_{1}+u_{2}$ and $e_{2}^{\prime}=A_{1} e_{1}^{\prime}+u_{2}^{\prime}$, then $P e_{2}=P A_{1} e_{1}+P u_{2}=P A_{1} P e_{1}+P u_{2}$ and $P e_{2}^{\prime}=P A_{1} e_{1}^{\prime}+P u_{2}^{\prime}=P A_{1} P e_{1}^{\prime}+P u_{2}^{\prime}$. So $P e_{2}=P e_{2}^{\prime}$ and the $F S\left[A_{1}, A_{2}\right]$ is causal. On the other hand,

$$
\begin{aligned}
P e_{2} & =P u_{2}+P A_{1}\left(I+A_{2} A_{1}\right)^{-1}\left(u_{1}-A_{2}\right) \\
& =P u_{2}+P A_{1} P\left(I+A_{2} A_{1}\right)^{-1}\left(u_{1}-A_{2} u_{2}\right) \\
& =P u_{2}+P A_{1} P\left(I+A_{2} A_{1}\right)^{-1} P\left(u_{1}-A_{2} u_{2}\right) \\
& =P u_{2}+A_{1 P} N_{P}^{-1}\left(P u_{1}-A_{2 P} u_{2}\right)
\end{aligned}
$$

likewise

$$
P e_{2}^{\prime}=P u_{2}^{\prime}+A_{1 P} N_{P}^{-1}\left(P u_{1}^{\prime}-A_{2 P} u_{2}^{\prime}\right)
$$

therfore

$$
\begin{aligned}
\left\|P\left(e_{2}-e_{2}^{\prime}\right)\right\| \leq & \left\|u_{2}-u_{2}^{\prime}\right\|+ \\
& +\left\|A_{1 P} N_{P}^{-1}\left(P u_{1}-A_{2 P} u_{2}\right)-A_{1 P} N_{P}^{-1}\left(P u_{1}^{\prime}-A_{2 P} u_{2}^{\prime}\right)\right\| \\
\leq & \left\|u_{2}-u_{2}^{\prime}\right\|+\left\|A_{1 P}\right\|^{*}\left\|N_{P}^{-1}\right\|^{*}\left\|P\left(u_{1}-u_{1}^{\prime}\right)+A_{2 P}\left(u_{2}^{\prime}-u_{2}\right)\right\| \\
\leq & \left\|u_{2}-u_{2}^{\prime}\right\|+\left\|A_{1 P}\right\|^{*}\left\|N_{P}^{-1}\right\|^{*}\left(\left\|u_{1}-u_{1}^{\prime}\right\|+\left\|A_{2 P}\right\|\left\|u_{2}^{\prime}-u_{2}\right\|\right) \\
\leq & \left\|u_{2}-u_{2}^{\prime}\right\|+\lambda k k^{*}\left(\left\|u_{1}-u_{1}^{\prime}\right\|+k\left\|u_{2}^{\prime}-u_{2}\right\|\right) \\
\leq & \lambda k k^{*}\left\|u_{1}-u_{1}^{\prime}\right\|+\left(1+\lambda k^{2} k^{*}\right)\left\|u_{2}-u_{2}^{\prime}\right\|,
\end{aligned}
$$

hence $e_{2}-e_{2}^{\prime} \in H$ and

$$
\left\|e_{2}-e_{2}^{\prime}\right\| \leq \lambda k k^{*}\left\|u_{1}-u_{1}^{\prime}\right\|+\left(1+\lambda k^{2} k^{*}\right)\left\|u_{2}-u_{2}^{\prime}\right\| .
$$

The second result of normality in this work is:

Theorem 3.2. Let $A_{1}, A_{2}: H_{e} \rightarrow H_{e}$ be two causal operators whose $A_{1}$ is linear, and for all $P \in \mathcal{P}, A_{1 P}$ and $A_{2 P}$, the respective restrictions of $P A_{1}$ and $P A_{2}$ to $H_{P}$. It is assumed that, for any $P \in \mathcal{P}$

(i) $A_{1 P} \in$ Lip and $\mu_{A_{1 P}}>0$.

(ii) $A_{2 P} \in \mathcal{M}, A_{2 P}$ is hemicontinuous and $\mu_{A_{2 P}} \leq 0$.

(iii) $\mu_{A_{1 P}}+\mu_{A_{2 P}}\left\|A_{1 P}\right\|^{2}>0$.

Then the $F S\left[A_{1}, A_{2}\right]$ on $H_{e}$ is normal and causal.

Moreover, if $\left\|A_{1 P}\right\| \leq k,\left(\mu_{A_{1 P}}+\mu_{A_{2 P}}\left\|A_{1 P}\right\|^{2}\right)^{-1} \leq \lambda ;\left(u_{1}, u_{2}\right) \mapsto\left(e_{1}, e_{2}\right) \in H_{e}^{2}$ and $\left(u_{1}^{\prime}, u_{2}^{\prime}\right) \mapsto\left(e_{1}^{\prime}, e_{2}^{\prime}\right) \in H_{e}^{2}$ with $\left(u_{1-} u_{1}^{\prime}, u_{2}-u_{2}^{\prime}\right) \in$ $H^{2}$, then, $\left(e_{1-} e_{1}^{\prime}, e_{2}-e_{2}^{\prime}\right) \in H^{2}$,

$$
\left\|e_{1-} e_{1}^{\prime}\right\| \leq \lambda k\left\|u_{1}-u_{1}^{\prime}\right\|+(1+\lambda k) \mu_{A_{1 P}}^{-1}\left\|u_{2}-u_{2}^{\prime}\right\|,
$$

and

$$
\left\|e_{2} e_{2}^{\prime}\right\| \leq \lambda k^{2}\left\|u_{1}-u_{1}^{\prime}\right\|+\left(1+\left(1+\lambda k^{2}\right) \mu_{A_{1 P}}^{-1}\right)\left\|u_{2}-u_{2}^{\prime}\right\|,
$$

where $\lambda$ and $k$ are two positive real constants.

Proof. Let $z \in H_{e}$ and be the two operators $M_{z}, B_{z}: H_{e} \rightarrow H_{e}$ defined respectively by: $M_{z} x=x+A_{2}\left(z+A_{1} x\right)$ and $B_{z} x=z+A_{1} x$ for all $x \in H_{e}$. It is clear that $M_{z}=I+A_{2} B_{z}$ and that, for all $P \in \mathcal{P}, P B_{z}=P\left(z+A_{1}\right)=P z+P A_{1} P=$ $P\left(z+A_{1} P\right)=P B_{z} P$ and

$$
\begin{aligned}
P M_{z} P & =P\left(I+A_{2} B_{z}\right) P=P\left(P+A_{2} B_{z} P\right)=P^{2}+P A_{2} B_{z} P \\
& =P^{2}+P A_{2} P B_{z} P=P^{2}+P A_{2} P B_{z}=P+P A_{2} B_{z} \\
& =P\left(I+A_{2} B_{z}\right)=P M_{z}
\end{aligned}
$$


therfore $B_{z}$ and $M_{z}$ are causal. With the same argumentation used in the proof of theorem 3.1, we have on $H_{P}$, for all $P \in \mathcal{P}, P M_{z}=P\left(I+A_{2} B_{z}\right)=I+P A_{2} B_{z}$ and therfore $P M_{z}=I+P A_{2} P B_{z}=I+A_{2 P} B_{P z}=N_{P}$, where $B_{P z}=z+A_{1 P}$. Then the operator $N_{P}$ is the restriction to $H_{P}$ of the oprerator $P M_{z}$ and $N_{P}$ satisfy the conditions of lemma 4.4, so it is causal, invertible, the inverse $N_{P}^{-1} \in \operatorname{Lip}$, and $\left\|N_{P}^{-1}\right\|^{*} \leq\left\|A_{1 P}\right\|\left(\mu_{A_{1 P}}+\mu_{A_{2 P} P}\left\|A_{1 P}\right\|^{2}\right)^{-1} \leq \lambda k\left(\operatorname{Lip} \subset \mathcal{M}, \mu_{A_{1 P}}=\mu_{B_{P_{z}}}\right.$ and $\left.\left\|A_{1 P}\right\|=\left\|B_{P_{z}}\right\|^{*}\right)$. It is deduced (cf, lemma 4.1) that the operator $M_{z}$ is invertible. According to corollary 4.2, the $F S$ $\left[A_{1}, A_{2}\right]$ is normal and the solution is given (see (3)) by

$$
\left(e_{1}, e_{2}\right)=\left(M_{u_{2}}^{-1} u_{1}, u_{2}+A_{1} M_{u_{2}}^{-1} u_{1}\right) .
$$

Using (5), on get

$$
\left.\left(e_{1}, e_{1}^{\prime}\right)=\left(N^{-1}\left(u_{1}+A_{1}^{-1} u_{2}\right)-A_{1}^{-1} u_{2}, N^{-1}\left(u_{1}^{\prime}+A_{1}^{-1} u_{2}^{\prime}\right)-A_{1}^{-1} u_{2}^{\prime}\right)\right)
$$

where $N=I+A_{2} A_{1}$, so

$$
\begin{aligned}
\left\|P\left(e_{1}-e_{1}^{\prime}\right)\right\| \leq & \left\|P N^{-1}\left(P u_{1}+P A_{1}^{-1} u_{2}\right)-P N^{-1}\left(P u_{1}^{\prime}+P A_{1}^{-1} u_{2}^{\prime}\right)\right\| \\
& +\left\|P A_{1}^{-1} u_{2}^{\prime}-P A_{1}^{-1} u_{2}\right\| \\
\leq & \left\|N_{P}^{-1}\right\|\left\|^{*}\right\| u_{1}-u_{1}^{\prime}\left\|+\left(\left\|N_{P}^{-1}\right\|^{*}+1\right)\right\| A_{1 P}^{-1}\|\| u_{2}-u_{2}^{\prime} \| \\
\leq & \lambda k\left\|u_{1}-u_{1}^{\prime}\right\|+(1+\lambda k) \mu_{A_{1 P}}^{-1}\left\|u_{2}-u_{2}^{\prime}\right\|,
\end{aligned}
$$

where lemma 4.1 was used. From where

$$
\left\|e_{1}-e_{1}^{\prime}\right\| \leq \lambda k\left\|u_{1}-u_{1}^{\prime}\right\|+(1+\lambda k) \mu_{A_{1 P}}^{-1}\left\|u_{2}-u_{2}^{\prime}\right\| .
$$

Using the first inequality above, we deduce the causality of the $F S\left[A_{1}, A_{2}\right]$ as in the proof of theorem3.1. On the other hand

$$
\begin{gathered}
\left(e_{2}, e_{2}^{\prime}\right)=\left(u_{2}+A_{1} N^{-1}\left(u_{1}+A_{1}^{-1} u_{2}\right)-A_{1}^{-1} u_{2},\right. \\
\left.u_{2}^{\prime}+A_{1} N^{-1}\left(u_{1}^{\prime}+A_{1}^{-1} u_{2}^{\prime}\right)-A_{1}^{-1} u_{2}^{\prime}\right)
\end{gathered}
$$

therefore

$$
\begin{aligned}
P\left(e_{2}-e_{2}^{\prime}\right)= & P\left(u_{2}-u_{2}^{\prime}\right)+P A_{1} P N^{-1}\left(u_{1}+A_{1}^{-1} u_{2}\right) \\
& -P A_{1} N^{-1}\left(u_{1}^{\prime}+A_{1}^{-1} u_{2}^{\prime}\right)+P A_{1}^{-1}\left(u_{2}^{\prime}-u_{2}\right) \\
= & P\left(u_{2}-u_{2}^{\prime}\right)+A_{1 P} N_{P}^{-1} P\left(u_{1}+A_{1}^{-1} u_{2}\right) \\
& -A_{1 P} N_{P}^{-1} P\left(u_{1}^{\prime}+A_{1}^{-1} u_{2}^{\prime}\right)+A_{1 P}^{-1} P\left(u_{2}^{\prime}-u_{2}\right) \\
= & P\left(u_{2}-u_{2}^{\prime}\right)+A_{1 P} N_{P}^{-1}\left(P u_{1}+P A_{1}^{-1} u_{2}\right) \\
& -A_{1 P} N_{P}^{-1}\left(P u_{1}^{\prime}+P A_{1}^{-1} u_{2}^{\prime}\right)+A_{1 P}^{-1} P\left(u_{2}^{\prime}-u_{2}\right) \\
= & P\left(u_{2}-u_{2}^{\prime}\right)+A_{1 P} N_{P}^{-1}\left(P u_{1}+A_{1 P}^{-1} P u_{2}\right) \\
& -A_{1 P} N_{P}^{-1}\left(P u_{1}^{\prime}+A_{1 P}^{-1} P u_{2}^{\prime}\right)+A_{1 P}^{-1} P\left(u_{2}^{\prime}-u_{2}\right),
\end{aligned}
$$

and

$$
\begin{aligned}
\left\|P\left(e_{2}-e_{2}^{\prime}\right)\right\| \leq & \left\|u_{2}-u_{2}^{\prime}\right\|\left(1+\left\|A_{1 P}^{-1}\right\|\right) \\
& +\left\|A_{1 P} N_{P}^{-1}\left(P u_{1}+A_{1 P}^{-1} P u_{2}\right)-A_{1 P} N_{P}^{-1}\left(P u_{1}^{\prime}+A_{1 P}^{-1} P u_{2}^{\prime}\right)\right\| \\
\leq & \left(1+\left\|A_{1 P}^{-1}\right\|\right)\left\|u_{2}-u_{2}^{\prime}\right\|+\left\|A_{1 P}\right\|\left\|N_{P}^{-1}\right\|^{*}\left\|u_{1}-u_{1}^{\prime}\right\| \\
& +\left\|A_{1 P}\right\|\left\|N_{P}^{-1}\right\|^{*}\left\|A_{1 P}^{-1}\right\|\left\|u_{2}-u_{2}^{\prime}\right\| \\
\leq & \lambda k^{2}\left\|u_{1}-u_{1}^{\prime}\right\|+\left(1+\left(1+\lambda k^{2}\right) \mu_{A_{1 P}}^{-1}\right)\left\|u_{2}-u_{2}^{\prime}\right\| .
\end{aligned}
$$

From where 


$$
\left\|e_{2}-e_{2}^{\prime}\right\| \leq \lambda k^{2}\left\|u_{1}-u_{1}^{\prime}\right\|+\left(1+\left(1+\lambda k^{2}\right) \mu_{A_{1 P}}^{-1}\right)\left\|u_{2}-u_{2}^{\prime}\right\| .
$$

\subsection{Linearization of $F S\left[A_{1}, A_{2}\right]$ on $H_{e}$}

Let a non linair $F S\left[A_{1}, A_{2}\right]$ on $H_{e}$. The main idea in this subsection is to linearize $\left[A_{1}, A_{2}\right]$ in the neighbourhood of the zero. We then consider a linear $F S\left[A_{1}^{0}, A_{2}^{0}\right]$ on $H_{e}$ and prove that, if $\left(u_{1}, u_{2}\right) \mapsto\left(e_{1}, e_{2}\right) \in H_{e}^{2}$ and $\left(u_{1}, u_{2}\right) \mapsto\left(e_{1}^{0} e_{2}^{0}\right) \in H_{e}^{2}$ where $\left(u_{1}, u_{2}\right) \in H_{P}^{2}$ with $\left\|u_{1}\right\|,\left\|u_{2}\right\| \leq r(r>0)$ and $\left(e_{1}, e_{2}\right),\left(e_{1}^{0} e_{2}^{0}\right)$ the respective solutions of $\left[A_{1}, A_{2}\right]$ and $\left[A_{1}^{0}, A_{2}^{0}\right]$. There existes $k_{11}, k_{12}, k_{21}$ and $k_{22}$ positive real constants such that

$$
\left\|e_{1}-e_{1}^{0}\right\| \leq k_{11}\left\|u_{1}\right\|+k_{12}\left\|u_{2}\right\|,
$$

and

$$
\left\|e_{2}-e_{2}^{0}\right\| \leq k_{21}\left\|u_{1}\right\|+k_{22}\left\|u_{2}\right\| .
$$

The inequalities above are given by theorem 3.3. To have suitable estimates, in the sense that the solutions of the two systems become sufficiently close. It is assumed that, one of the two operators of $\left[A_{1}, A_{2}\right]$ is linear, this is the subject of theorems 3.4 and 3.5. Before establishing the first linearization result of this part, we need the following two notions:

\section{Definition 3.1.}

(i) We say that a normal FS $\left[A_{1}, A_{2}\right]$ on $H_{e}$ is Lipschitz continuous for the first inputs, if there are positive numbers $\lambda_{11}$ and $\lambda_{21}$ such that $\left\|e_{1}-e_{1}^{\prime}\right\| \leq \lambda_{11}\left\|u_{1}-u_{1}^{\prime}\right\|$ and $\left\|e_{2}-e_{2}^{\prime}\right\| \leq \lambda_{12}\left\|u_{1}-u_{1}^{\prime}\right\|$ where $\left(u_{1}, u^{*}\right) \mapsto\left(e_{1}, e_{2}\right),\left(u_{1}^{\prime}, u^{*}\right) \mapsto\left(e_{1}^{\prime} e_{2}^{\prime}\right)$ and $u_{1}-u_{1}^{\prime} \in H$.

(ii) We say that a normal $F S\left[A_{1}, A_{2}\right]$ on $H_{e}$ is Lipschitz continuous for both inputs, if there are positive numbers $\lambda_{11}, \lambda_{12}$, $\lambda_{21}$ and $\lambda_{22}$ such that:

$$
\left\|e_{1}-e_{1}^{\prime}\right\| \leq \lambda_{11}\left\|u_{1}-u_{1}^{\prime}\right\|+\lambda_{12}\left\|u_{2}-u_{2}^{\prime}\right\|
$$

and

$$
\left\|e_{2}-e_{2}^{\prime}\right\| \leq \lambda_{21}\left\|u_{1}-u_{1}^{\prime}\right\|+\lambda_{22}\left\|u_{2}-u_{2}^{\prime}\right\|
$$

where $\left(u_{1}, u_{2}\right) \mapsto\left(e_{1}, e_{2}\right),\left(u_{1}^{\prime}, u_{2}^{\prime}\right) \mapsto\left(e_{1}^{\prime}, e_{2}^{\prime}\right)$ and $\left(u_{1}-u_{1}^{\prime}, u_{2}-u_{2}^{\prime}\right) \in H^{2}$.

Let in the Hilbert space $H_{P}$ be the closed ball $B_{r}$, centered in zero with radius $r>0$. Then we have:

Theorem 3.3. Let $A_{1}, A_{2}: H_{e} \mapsto H_{e}$ be the causal operators. For all $P \in P, A_{1 P}, A_{2 P}$, the respective restrictions of $P A_{1}$, $P A_{2}$ to $H_{P}$. Assume that:

(a) $A_{1 P}, A_{2 P} \in$ Lip for any $P \in \mathcal{P}$.

(b) There exist a linear and causal operator $A_{1}^{0}: H_{e} \mapsto H_{e}$ such that: for all $x \in B_{v r}$

$$
\left\|\left(A_{1 P}-A_{1 P}^{0}\right) x\right\| \leq a_{1}\|x\|
$$

where for all $P \in \mathcal{P}, A_{1 P}^{0}$ is the restriction of $P A_{1}^{0}$ to $H_{P}, 0 \leq a_{1} \leq \mu_{A_{1 P}}$ and $v=\mu_{A_{1 P}}^{-1}\left(\mu_{A_{2 P}}+\mu_{A_{1 P}}\left\|A_{1 P}\right\|^{*-2}\right)^{-1}$.

(c) There exist a linear and causal operator $A_{2}^{0}: H_{e} \mapsto H_{e}$ such that: for all $x \in B_{\left(1+\nu\left\|A_{1}\right\|^{*}\right) r}$

$$
\left\|\left(A_{2 P}-A_{2 P}^{0}\right) x\right\| \leq a_{2}\|x\|
$$

where for all $P \in \mathcal{P}, A_{2 P}^{0}$ the restriction of $P A_{2}^{0}$ to $H_{P}$ and $a_{2}>0$.

(d) $\left(\mu_{A_{2 P}}-a_{2}\right)+\left(\mu_{A_{1 P}}-a_{1}\right)\left(a_{1+}\left\|A_{1 P}\right\|^{*}\right)^{-2}>0$. Then:

(i) The $F S^{\prime} s\left[A_{1}, A_{2}\right]$ and $\left[A_{1}^{0}, A_{2}^{0}\right]$ on $H_{e}$ are normal and Lipschitz continuous for the first inputs.

(ii) If $\left(u_{1}, u_{2}\right) \mapsto\left(e_{1}, e_{2}\right) \in H_{e}^{2}$ and $\left(u_{1}, u_{2}\right) \mapsto\left(e_{1}^{0} e_{2}^{0}\right) \in H_{e}^{2}$ where $\left(u_{1}, u_{2}\right) \in H_{P}^{2}$ with $\left\|u_{1}\right\|,\left\|u_{2}\right\| \leq r$ and $\left(e_{1}, e_{2}\right),\left(e_{1}^{0} e_{2}^{0}\right)$ the respective solutions of $\left[A_{1}, A_{2}\right]$ and $\left[A_{1}^{0}, A_{2}^{0}\right]$. We have:

$$
\begin{aligned}
& \left\|e_{1}-e_{1}^{0}\right\| \leq k_{11}\left\|u_{1}\right\|+k_{12}\left\|u_{2}\right\| ; \\
& \left\|e_{2}-e_{2}^{0}\right\| \leq k_{21}\left\|u_{1}\right\|+k_{22}\left\|u_{2}\right\|,
\end{aligned}
$$


where

$$
\begin{gathered}
k_{11}=k v\left(a_{2}+\left\|A_{1 P}\right\|^{*}+a_{1}\left\|A_{2 P}^{0}\right\|\right), k_{12}=k a_{2} \\
k_{21}=a_{1} v+\left\|A_{1 P}^{0}\right\| k_{11}, k_{22}=k\left\|A_{1 P}^{0}\right\| a_{2}
\end{gathered}
$$

and

$$
k=\left(\mu_{A_{1 P}}-a_{1}\right)
$$

Proof. Let $x \in B_{r}$, since $\left\|\left(A_{1 P}-A_{1 P}^{0}\right) x\right\| \leq a_{1}\|x\|$ so $A_{1 P} 0=0$, moreover for $x \neq 0$

$$
\left\|A_{1 P}^{0} x\right\| \leq\left\|\left(A_{1 P}-A_{1 P}^{0}\right) x\right\|+\left\|A_{1 P} x\right\| \leq\left(a_{1}+\left\|A_{1 P}\right\|^{*}\right)\|x\|,
$$

then $\left\|A_{1 P}^{0}\right\| \leq a_{1}+\left\|A_{1 P}\right\|^{*}$, hence it is bounded on $H_{p}$

On the other hand, $\left\langle A_{1 P}^{0} x, x\right\rangle=\left\langle A_{1 P} x, x\right\rangle+\left\langle A_{1 P}^{0} x-A_{1 P} x, x\right\rangle$ therefore

$$
\left\langle\left(A_{1 P}-A_{1 P}^{0}\right) x, x\right\rangle=\left\langle A_{1 P} x, x\right\rangle-\left\langle A_{1 P}^{0} x, x\right\rangle
$$

From the cauchy-schwarz inequality,

$$
\left\|\left\langle A_{1 P} x, x\right\rangle-\left\langle A_{1 P}^{0} x, x\right\rangle\right\| \leq\left\|\left(A_{1 P}-A_{1 P}^{0}\right) x\right\|\|x\| \leq a_{1}\|x\|^{2} .
$$

By definition of $\mu_{A_{1 P}}$, we have for all $x \in B_{v r}(x \neq 0),\left\langle A_{1 P} x, x\right\rangle \geq \mu_{A_{1 P}}\|x\|^{2}$ therefore, for all $x \in H_{P},\left\langle A_{1 P}^{0} x, x\right\rangle \geq$ $\left(\mu_{A_{1 P}}-a_{1}\right)\|x\|^{2}$, from where $\frac{\left\langle A_{1 P}^{0} x, x\right\rangle}{\|x\|^{2}} \geq \mu_{A_{1 P}}-a_{1}$, and thus $\mu_{A_{1 P}^{0}} \geq \mu_{A_{1 P}}-a_{1}>0$. The operator $A_{1 P}^{0}$ is linear and bounded so it is hemicontinuous, according to lemma 4.1, $A_{1 P}^{0}$ is invertible. It is similarly shown that $\left\|A_{2 P}^{0}\right\| \leq a_{2}+\left\|A_{2 P}\right\|^{*}$ and $\mu_{A_{2 P}^{0}} \geq \mu_{A_{2 P}}-a_{2}$. Let now, for all $x$ and $z$ in $H_{e}, M_{z} x=x+A_{2}\left(z+A_{1} x\right), M_{z}^{0} x=x+A_{2}^{0}\left(z+A_{1}^{0} x\right), M_{P z} x=x+A_{2 P}\left(z+A_{1 P} x\right)$, and $M_{P z}^{0} x=x+A_{2 P}^{0}\left(z+A_{1 P}^{0} x\right)$ or $M_{P z}=I+A_{2 P} B_{P z}$, and $M_{P z}^{0}=I+A_{2 P}^{0} B_{P z}^{0}$, (with $\left.B_{P z}=z+A_{1 P}, B_{P z}^{0}=z+A_{1 P}^{0}\right)$. Using, lemma 4.5, $M_{P z}$ and $M_{P z}^{0}$ are invertible and therefore according to corollary 4.2, the $F S\left[A_{1}, A_{2}\right]$ is normal, moreover (cf, lemma 4.2) $M_{P z}^{-1} \in \operatorname{Lip}$,

$$
\begin{aligned}
\left\|M_{P Z}^{-1}\right\|^{*} & \leq \mu_{B_{P_{z}}}^{-1}\left(\mu_{A_{2 P}}+\mu_{B_{P_{z}}}\left\|B_{P_{z}}\right\|^{*-2}\right)^{-1} \\
& =\mu_{A_{1 P}}^{-1}\left(\mu_{A_{2 P}}+\mu_{A_{1 P}}\left\|A_{1 P}\right\|^{*-2}\right)^{-1} \\
& =v .
\end{aligned}
$$

where $\mu_{B_{P z}}=\mu_{A_{1 P}}$ and $\left\|B_{P z}\right\|^{*}=\left\|A_{1 P}\right\|^{*}$.

Now, we demonstrate that $\left[A_{1}, A_{2}\right]$ is Lipschitz continuous for the first input. We know (cf lemma 4.5) that for all $P \in \mathcal{P}$, $P M_{z}^{-1}=N_{P}^{-1} P$ and $M_{z}^{-1}$ is causal, so

$$
\begin{aligned}
& P e_{1}=P M_{u_{2}}^{-1} u_{1}=P M_{u_{2}}^{-1} P u_{1}=N_{P}^{-1} P u_{1} ; \\
& P e_{1}^{\prime}=P M_{u_{2}}^{-1} u_{1}^{\prime}=P M_{u_{2}}^{-1} P u_{1}^{\prime}=N_{P}^{-1} P u_{1}^{\prime} .
\end{aligned}
$$

Since $N_{P}^{-1} \in \operatorname{Lip}\left(\right.$ cf lemma 4.2) with $N_{P}=I+A_{2 P} B_{z P}$, we have

$$
\begin{aligned}
\left\|P\left(e_{1}-e_{1}^{\prime}\right)\right\| & \leq\left\|N_{P}^{-1} P u_{1}-N_{P}^{-1} P u_{1}^{\prime}\right\| \\
& \leq\left\|N_{P}^{-1}\right\|^{*}\left\|P\left(u_{1}-u_{1}^{\prime}\right)\right\| \\
& \leq \lambda_{11}\left\|u_{1}-u_{1}^{\prime}\right\| .
\end{aligned}
$$

hence, $e_{1}-e_{1}^{\prime} \in H$ and $\left\|e_{1}-e_{1}^{\prime}\right\| \leq \lambda_{11}\left\|u_{1}-u_{1}^{\prime}\right\|$, where $\lambda_{11}=v$. 
On the other hand, $e_{2}=A_{1} e_{1}+u_{2}$ and $e_{2}^{\prime}=A_{1} e_{1}^{\prime}+u_{2}$ so

$$
\begin{aligned}
\left\|P\left(e_{2}-e_{2}^{\prime}\right)\right\| & \leq\left\|A_{1 P}\right\|^{*}\left\|e_{1}-e_{1}^{\prime}\right\| \\
& \leq \lambda_{11}\left\|A_{1 P}\right\|^{*}\left\|u_{1}-u_{1}^{\prime}\right\|,
\end{aligned}
$$

we deduce that $\left\|e_{2}-e_{2}^{\prime}\right\| \leq \lambda_{21}\left\|u_{1}-u_{1}^{\prime}\right\|$, where $\lambda_{21}=\left\|A_{1 P}\right\|^{*} \lambda_{11}$.

To demonstrate that $\left[A_{1}^{0}, A_{2}^{0}\right]$ is normal, it is sufficient to check that $\mu_{A_{2 P}^{0}}+\mu_{A_{1 P}^{0}}\left\|A_{1 P}^{0}\right\|^{*-2}>0$. We have $\mu_{A_{2 P}^{0}} \geq \mu_{A_{2 P}}-a_{2}$; $\mu_{A_{1 P}^{0}} \geq \mu_{A_{1 P}}-a_{1}$ and $\left\|A_{1 P}^{0}\right\| \leq a_{1}+\left\|A_{1 P}\right\|^{*}$, so

$$
\begin{aligned}
\mu_{A_{2 P}^{0}}+\mu_{A_{1 P}^{0}}\left\|A_{1 P}^{0}\right\|^{*-2} & \geq \mu_{A_{2 P}}-a_{2}+\mu_{A_{1 P}^{0}}\left\|A_{1 P}^{0}\right\|^{*-2} \\
& \geq \mu_{A_{2 P}}-a_{2}+\left(\mu_{A_{1 P}}-a_{1}\right)\left\|A_{1 P}^{0}\right\| \\
& \geq \mu_{A_{2 P}}-a_{2}+\left(\mu_{A_{1 P}}-a_{1}\right)\left(a_{1}+\left\|A_{1 P}\right\|^{*}\right)^{-1}>0 .
\end{aligned}
$$

Since $M_{P z}^{0}$ is invertible, $\left(M_{P z}^{0}\right)^{-1} \in$ Lip and

$$
\left\|\left(M_{P z}^{0}\right)^{-1}\right\|^{*} \leq \mu_{B_{P z}^{0}}^{-1}\left(\mu_{A_{2 P}^{0}}+\mu_{B_{P z}^{0}}\left\|B_{P z}^{0}\right\|^{*-2}\right)^{-1}
$$

therefore

$$
\left\|\left(M_{P z}^{0}\right)^{-1}\right\|^{*} \leq\left(\mu_{A_{1 P}}-a_{1}\right)^{-1}\left(\mu_{A_{2 P}^{0}}-a_{2}+\left(\mu_{A_{1 P}}-a_{1}\right)\left\|A_{1 P}^{0}\right\|^{*-2}\right)^{-1}
$$

The two operators $A_{1 P}^{0}, A_{2 P}^{0} \in$ Lip and they are hemicontinuous with $\mu_{A_{1 P}^{0}}>0$ and $\mu_{A_{2 P}^{0}}+\mu_{A_{1 P}^{0}}\left\|A_{1 P}^{0}\right\|^{*-2}>0$. According to lemma 4.2, $\left[A_{1}^{0}, A_{2}^{0}\right]$ is normal. The Lipschitzian continuity of $\left[A_{1}^{0}, A_{2}^{0}\right]$ is demonstrated in the same way as that of $\left[A_{1}, A_{2}\right]$. On the other hand, the operator $N_{P}^{0}=I+A_{2 P}^{0} A_{1 P}^{0}$ is such that: $A_{2 P}^{0} \in \operatorname{Lip}$ and it is hemicontinuous, $A_{1 P}^{0} \in \operatorname{Lip}, \mu_{A_{1 P}^{0}}>0$ and $\mu_{A_{2 P}^{0}}+\mu_{A_{1 P}^{0}}\left\|A_{1 P}^{0}\right\|^{*-2}>0$. By using lemma 4.2, $N_{P}^{0}$ is invertible, $N_{P}^{0-1} \in$ Lip and $\left\|N_{P}^{0-1}\right\|^{*} \leq \mu_{A_{1 P}^{0}}^{-1}\left(\mu_{A_{2 P}^{0}}+\mu_{A_{1 P}^{0}}\left\|A_{1 P}^{0}\right\|^{*-2}\right)^{-1} \leq$ $k$. Then we can write from (5)

$$
\begin{aligned}
M_{P z}^{-1} x-M_{P z}^{0-1} x= & M_{P z}^{-1} x-N_{P}^{0-1}\left(x+A_{1 P}^{0-1} z\right)+A_{1 P}^{0-1} z \\
= & M_{P z}^{-1} x-N_{P}^{0-1} x-N_{P}^{0-1} A_{1 P}^{0-1} z+A_{1 P}^{0-1} z \\
= & M_{P z}^{-1} x-N_{P}^{0-1} x+\left(I-N_{P}^{0-1}\right) A_{1 P}^{0-1} z \\
= & -N_{P}^{0-1}\left(M_{P z}-N_{P}^{0}\right) M_{P z}^{-1} x+N_{P}^{0-1}\left(N_{P}^{0}-I\right) A_{1 P}^{0-1} z \\
= & -N_{P}^{0-1}\left(M_{P z} \omega-N_{P}^{0} \omega\right)+N_{P}^{0-1} A_{2 P}^{0} A_{1 P}^{0} A_{1 P}^{0-1} z \\
= & -N_{P}^{0-1}\left(\omega+A_{2 P}\left(z+A_{1 P} \omega\right)-\omega-A_{2 P}^{0} A_{1 P}^{0} \omega\right)+N_{P}^{0-1} A_{2 P}^{0} z \\
= & -N_{P}^{0-1}\left(A_{2 P}\left(z+A_{1 P} \omega\right)-A_{2 P}^{0} A_{1 P}^{0} \omega\right)+N_{P}^{0-1} A_{2 P}^{0} z \\
= & -N_{P}^{0-1}\left[A_{2 P}\left(z+A_{1 P} \omega\right)-A_{2 P}^{0}\left(z+A_{1 P} \omega\right)\right. \\
& \left.+A_{2 P}^{0}\left(z+A_{1 P} \omega\right)-A_{2 P}^{0} A_{1 P}^{0} \omega\right]+N_{P}^{0-1} A_{2 P}^{0} z \\
= & -N_{P}^{0-1}\left(A_{2 P}-A_{2 P}^{0}\right)\left(z+A_{1 P} \omega\right)-N_{P}^{0-1}\left(A_{2 P}^{0}\left(z+A_{1 P} \omega\right)\right. \\
& \left.\left.-A_{2 P}^{0} A_{1 P}^{0} \omega\right)\right)+N_{P}^{0-1} A_{2 P}^{0} z \\
= & -N_{P}^{0-1}\left(A_{2 P}-A_{2 P}^{0}\right)\left(z+A_{1 P} \omega\right) \\
& -N_{P}^{0-1}\left(A_{2 P}^{0} z+A_{2 P}^{0} A_{1 P} \omega-A_{2 P}^{0} A_{1 P}^{0} \omega\right)+N_{P}^{0-1} A_{2 P}^{0} z \\
= & -N_{P}^{0-1}\left(A_{2 P}-A_{2 P}^{0}\right)\left(z+A_{1 P} \omega\right)-N_{P}^{0-1} A_{2 P}^{0}\left(A_{1 P}-A_{1 P}^{0}\right) \omega
\end{aligned}
$$

where $\omega=M_{P z}^{-1} x$. Since $\|\omega\|=\left\|M_{P z}^{-1} x\right\| \leq\left\|M_{P z}^{-1}\right\|^{*}\|x\| \leq v r, \forall x \in B_{r}$ then $\omega \in B_{v r}$ and $A_{1 P} 0=0$, so

$$
\begin{aligned}
\left\|z+A_{1 P} \omega\right\| & \leq\|z\|+\left\|A_{1 P} \omega\right\| \leq\|z\|+\left\|A_{1 P}\right\|^{*}\|\omega\| \\
& \leq\|z\|+v\left\|A_{1 P}\right\|^{*}\|x\|
\end{aligned}
$$


It is deduced that for all $x, z \in B_{r}, z+A_{1 P} \omega \in B_{\left(\|z\|+\nu \mid\left\|A_{1 P}\right\|^{*}\right) r}$ and

$$
\begin{aligned}
\left\|M_{P z}^{-1} x-M_{P z}^{0-1} x\right\| \leq & \left\|N_{P}^{0-1}\right\|\left\|\left(A_{2 P}-A_{2 P}^{0}\right)\left(z+A_{1 P} \omega\right)\right\| \\
& +\left\|N_{P}^{0-1}\right\|\left\|A_{2 P}^{0}\right\|\left\|\left(A_{1 P}-A_{1 P}^{0}\right) \omega\right\| \\
\leq & \left\|N_{P}^{0-1}\right\|\left[a_{2}\left\|z+A_{1 P} \omega\right\|+\left\|A_{2 P}^{0}\right\| a_{1}\|\omega\|\right] \\
\leq & k\left(a_{2}\|z\|+a_{2}\left\|A_{1 P}\right\|^{*}\|\omega\|\right)+k a_{1}\left\|A_{2 P}^{0}\right\|\|\omega\| \\
\leq & k a_{2}\|z\|+k\|\omega\|\left(a_{2}\left\|A_{1 P}\right\|^{*}+a_{1}\left\|A_{2 P}^{0}\right\|\right) \\
\leq & k a_{2}\|z\|+v k\left(a_{2}\left\|A_{1 P}\right\|^{*}+a_{1}\left\|A_{2 P}^{0}\right\|\right)\|x\| \\
\leq & k_{11}\|x\|+k_{12}\|z\|,
\end{aligned}
$$

hence

$$
\left\|e_{1}-e_{1}^{0}\right\| \leq k_{11}\left\|u_{1}\right\|+k_{12}\left\|u_{2}\right\| .
$$

On the other hand,

$$
\begin{aligned}
\left\|e_{2}-e_{2}^{0}\right\| & \leq\left\|A_{1 P} M_{u_{2}}^{-1} u_{1}-A_{1 P}^{0} M_{u_{2}}^{0-1} u_{1}\right\| \\
& =\left\|A_{1 P} M_{u_{2}}^{-1} u_{1}-A_{1 P}^{0} M_{u_{2}}^{-1} u_{1}+A_{1 P}^{0} M_{u_{2}}^{-1} u_{1}-A_{1 P}^{0} M_{u_{2}}^{0-1} u_{1}\right\| \\
& =\left\|\left(A_{1 P}-A_{1 P}^{0}\right) M_{u_{2}}^{-1} u_{1}+A_{1 P}^{0}\left(M_{u_{2}}^{-1} u_{1}-M_{u_{2}}^{0-1} u_{1}\right)\right\| \\
& \leq\left\|A_{1 P}-A_{1 P}^{0}\right\|\left\|M_{u_{2}}^{-1} u_{1}\right\|+\left\|A_{1 P}^{0}\right\|\left\|M_{u_{2}}^{-1} u_{1}-M_{u_{2}}^{0-1} u_{1}\right\| \\
& \leq a_{1} v\left\|u_{1}\right\|+\left\|A_{1 P}^{0}\right\|\left(k_{11}\left\|u_{1}\right\|+k_{12}\left\|u_{2}\right\|\right) \\
& \leq\left(a_{1} v+\left\|A_{1 P}^{0}\right\| k_{11}\right)\left\|u_{1}\right\|+k_{12}\left\|A_{1 P}^{0}\right\|\left\|u_{2}\right\| \\
& \leq k_{21}\left\|u_{1}\right\|+k_{22}\left\|u_{2}\right\|,
\end{aligned}
$$

where

$$
k_{21}=a_{1} v+\left\|A_{1 P}^{0}\right\| k_{11} \text { and } k_{22}=\left\|A_{1 P}^{0}\right\| k_{12} .
$$

The second linearization result is:

Theorem 3.4. Let $A_{1}, A_{2}: H_{e} \mapsto H_{e}$ be, the causal operators whose $A_{2}$ is linear, and let for all $P \in P, A_{1 P}$ and $A_{2 P}$ be the respective restrictions of $P A_{1}, P A_{2}$, to $H_{P}$. we suppose that:

a) $A_{1 P} \in$ Lip and $\mu_{A_{1 P}} \leq 0$ for any $P \in \mathcal{P}$.

(b) $A_{2 P} \in \mathcal{M}$ and $\mu_{A_{2 P}}>0$ for any $P \in \mathcal{P}$.

(c) There exists a linear and causal operator, $A_{1}^{0}: H_{e} \mapsto H_{e}$ with $\mu_{A_{1 P}^{0}} \leq 0$, and $a_{1} \geq 0$ such that:

for all $x \in B_{\varpi\left(1+\left\|A_{2 P}\right\|\right) r}$

$$
\left\|\left(A_{1 P}-A_{1 P}^{0}\right) x\right\| \leq a_{1}\|x\|
$$

where for all $P \in \mathcal{P}, A_{1 P}^{0}$ is the restriction of $P A_{1}^{0}$ to $H_{P}$ and

$$
\varpi=\left\|A_{2 P}\right\|\left(\mu_{A_{2 P}}+\mu_{A_{1 P}}\left\|A_{2 P}\right\|^{2}\right)^{-1} .
$$

(d) $\mu_{A_{2 P}}+\left(\mu_{A_{1 P}}-a_{1}\right)\left\|A_{2 P}\right\|^{2}>0$. Then:

(i) The $F S^{\prime} s,\left[A_{1}, A_{2}\right]$ and $\left[A_{1}^{0}, A_{2}\right]$ on $H_{e}$, are normal and Lipschitz continuous for both inputs.

(ii) If $\left(u_{1}, u_{2}\right) \mapsto\left(e_{1}, e_{2}\right) \in H_{e}^{2} ;\left(u_{1}, u_{2}\right) \mapsto\left(e_{1}^{0} e_{2}^{0}\right) \in H_{e}^{2}$ where $\left(u_{1}, u_{2}\right) \in H_{P}^{2}$ with $\left\|u_{1}\right\|,\left\|u_{2}\right\| \leq r$ and $\left(e_{1}, e_{2}\right) ;\left(e_{1}^{0}, e_{2}^{0}\right)$ the respective solutions of $\left[A_{1}, A_{2}\right]$ and $\left[A_{1}^{0}, A_{2}\right]$. Then

$$
\left\|e_{1}-e_{1}^{0}\right\| \leq \lambda\left\|u_{1}\right\|+\lambda\left\|A_{2 P}\right\|\left\|u_{2}\right\|
$$

and

$$
\left\|e_{2}-e_{2}^{0}\right\| \leq\left(a_{1} \varpi+\lambda\left\|A_{1 P}^{0}\right\|\right)\left(\left\|u_{1}\right\|+\left\|A_{2 P}\right\|\left\|u_{2}\right\|\right)
$$


where

$$
\lambda=a_{1}\left\|A_{2 P}\right\|^{3}\left(\mu_{A_{2 P}}+\mu_{A_{1 P}}\left\|A_{2 p}\right\|^{2}\right)^{-1}\left(\mu_{A_{2 P}}+\mu_{A_{1 P}^{0}}\left\|A_{2 P}\right\|^{2}\right)^{-1} .
$$

Proof. Let for all $x$ and $z$ in $H_{e}, M_{p z} x=x+A_{2 P}\left(z+A_{1 P} x\right) ; M_{P z}^{0} x=x+A_{2 P}^{0}\left(z+A_{1 P}^{0} x\right) ; B_{P z}=z+A_{1 P}$ and $B_{p z}^{0}=z+A_{1 P}^{0}$. The operators $M_{P z}$ and $M_{P z}^{0}$ are causal; $M_{P z}$ and $M_{P z}^{0}$ are invertible. Indeed, $A_{1 P}$ is hemicontinuous, so $M_{P z}$ and $M_{P z}^{0}$ satisfy the conditions of lemma 4.3. Then $M_{z}$ and $M_{z}^{0}$ are invertible (see lemma 4.4).

Demonstrate that $\left[A_{1}, A_{2}\right]$ is Lipschitz continuous for both inputs. We know from (4) that:

$$
\begin{aligned}
& e_{1}=\left(I+A_{2} A_{1}\right)^{-1}\left(u_{1}-A_{2} u_{2}\right)=M_{P z}^{-1}\left(u_{1}-A_{2 P} u_{2}\right) ; \\
& e_{2}=u_{2}+A_{1}\left(I+A_{2} A_{1}\right)^{-1}\left(u_{1}-A_{2} u_{2}\right)
\end{aligned}
$$

therefore (see lemma 4.6)

$$
\begin{aligned}
P e_{1} & =P M_{P z}^{-1}\left(u_{1}-A_{2 P} u_{2}\right)=N_{P}^{-1} P\left(u_{1}-A_{2 P} u_{2}\right) \\
& =N_{P}^{-1}\left(P u_{1}-A_{2 P} P u_{2}\right) ; \\
P e_{1}^{\prime} & =N_{P}^{-1}\left(P u_{1}^{\prime}-A_{2 P} P u_{2}^{\prime}\right),
\end{aligned}
$$

and

$$
\begin{aligned}
\left\|P\left(e_{1}-e_{1}^{\prime}\right)\right\| & =\left\|N_{P}^{-1}\left(P u_{1}-A_{2 P} P u_{2}\right)-N_{P}^{-1}\left(P u_{1}^{\prime}-A_{2 P} P u_{2}^{\prime}\right)\right\| \\
& \leq\left\|N_{P}^{-1}\right\|^{*}\left\|P\left(u_{1}-u_{1}^{\prime}\right)-A_{2 P} P\left(u_{2}-u_{2}^{\prime}\right)\right\| \\
& \leq\left\|N_{P}^{-1}\right\|^{*}\left(\left\|u_{1}-u_{1}^{\prime}\right\|+\left\|A_{2 P}\right\|\left\|u_{2}-u_{2}^{\prime}\right\|\right) \\
& \leq \varpi\left(\left\|u_{1}-u_{1}^{\prime}\right\|+\left\|A_{2 P}\right\|\left\|u_{2}-u_{2}^{\prime}\right\|\right),
\end{aligned}
$$

from where

$$
\left\|e_{1}-e_{1}^{\prime}\right\| \leq \lambda_{11}\left\|u_{1}-u_{1}^{\prime}\right\|+\lambda_{12}\left\|A_{2 P}\right\|\left\|u_{2}-u_{2}^{\prime}\right\|,
$$

where $\lambda_{11}=\varpi$ and $\lambda_{12}=\varpi\left\|A_{2 P}\right\|$.

Always from (4)

$$
\begin{aligned}
e_{2} & =u_{2}+A_{1}\left(\left(I+A_{2} A_{1}\right)^{-1}\left(u_{1}-A_{2} u_{2}\right)\right) \\
& =u_{2}+A_{1 P} M_{P z}^{-1}\left(u_{1}-A_{2 P} u_{2}\right) ; \\
e_{2}^{\prime} & =u_{2}^{\prime}+A_{1}\left(\left(I+A_{2} A_{1}\right)^{-1}\left(u_{1}^{\prime}-A_{2} u_{2}^{\prime}\right)\right) \\
& =u_{2}^{\prime}+A_{1 P} M_{P z}^{-1}\left(u_{1}^{\prime}-A_{2 P} u_{2}^{\prime}\right),
\end{aligned}
$$

therefore

$$
\begin{aligned}
P e_{2} & =P u_{2}+P A_{1 P} M_{P z}^{-1}\left(u_{1}-A_{2 P} u_{2}\right) \\
& =P u_{2}+A_{1 P} N_{P}^{-1}\left(P u_{1}-A_{2 P} P u_{2}\right) ; \\
P e_{2}^{\prime} & =P u_{2}^{\prime}+P A_{1 P} M_{P z}^{-1}\left(u_{1}^{\prime}-A_{2 P} u_{2}^{\prime}\right) \\
& =P u_{2}^{\prime}+A_{1 P} N_{P}^{-1}\left(P u_{1}^{\prime}-A_{2 P} P u_{2}^{\prime}\right)
\end{aligned}
$$

then

$$
\begin{aligned}
P\left(e_{2}-e_{2}^{\prime}\right) & =P\left(u_{2}-u_{2}^{\prime}\right)+A_{1 P} N_{P}^{-1}\left(\left(P u_{1}-A_{2 P} P u_{2}\right)-\left(P u_{1}^{\prime}-A_{2 P} P u_{2}^{\prime}\right)\right) \\
& =P\left(u_{2}-u_{2}^{\prime}\right)+A_{1 P} N_{P}^{-1}\left(P\left(u_{1}-u_{1}^{\prime}\right)+A_{2 P} P\left(u_{2}-u_{2}^{\prime}\right)\right)
\end{aligned}
$$

and 


$$
\begin{aligned}
\left\|P\left(e_{2}-e_{2}^{\prime}\right)\right\| & \leq\left\|P\left(u_{2}-u_{2}^{\prime}\right)\right\|+\left\|A_{1 P} N_{P}^{-1}\left(P\left(u_{1}-u_{1}^{\prime}\right)+A_{2 P} P\left(u_{2}-u_{2}^{\prime}\right)\right)\right\| \\
& \leq\left\|P\left(u_{2}-u_{2}^{\prime}\right)\right\|+\left\|A_{1 P} N_{P}^{-1}\left(P\left(u_{1}-u_{1}^{\prime}\right)+A_{2 P} P\left(u_{2}-u_{2}^{\prime}\right)\right)\right\| \\
& \leq\left\|u_{2}-u_{2}^{\prime}\right\|+\left\|A_{1 P}\right\|\left\|N_{P}^{-1}\right\|^{*}\left(\left\|u_{1}-u_{1}^{\prime}\right\|+\left\|A_{2 P}\right\|\left\|u_{2}-u_{2}^{\prime}\right\|\right) \\
& \leq\left\|u_{2}-u_{2}^{\prime}\right\|\left(1+\varpi\left\|A_{1 P}\right\|\left\|A_{2 P}\right\|\right)+\varpi\left\|A_{1 P}\right\|\left\|u_{1}-u_{1}^{\prime}\right\| \\
& \leq \lambda_{21}\left\|u_{1}-u_{1}^{\prime}\right\|+\lambda_{22}\left\|u_{2}-u_{2}^{\prime}\right\|,
\end{aligned}
$$

where $\lambda_{21}=\varpi\left\|A_{1 P}\right\|$ and $\lambda_{22}=1+\lambda_{21}\left\|A_{2 P}\right\|$.

Then

$$
\left\|e_{2}-e_{2}^{\prime}\right\| \leq \lambda_{21}\left\|u_{1}-u_{1}^{\prime}\right\|+\lambda_{22}\left\|u_{2}-u_{2}^{\prime}\right\| .
$$

To estimate the solutions of $\left[A_{1}, A_{2}\right]$ and $\left[A_{1}^{0}, A_{2}^{0}\right]$, notice first that $\forall x \in B_{\varpi\left(1+\left\|A_{2 P}\right\|\right)},\left\|N_{P}^{-1} x\right\| \leq\left\|N_{P}^{-1}\right\|^{*}\|x\| \leq \varpi\|x\| \leq$ $\varpi\left(1+\left\|A_{2 P}\right\|\right) r$, so $N_{P}^{-1} x \in B_{\varpi\left(1+\left\|A_{2 P}\right\|\right) r}$. Since

$$
\begin{aligned}
\left\|N_{P}^{-1} x-N_{P}^{0-1} x\right\| & =\left\|N_{P}^{0-1}\left(N_{P}^{0}-N_{P}\right) N_{P}^{-1} x\right\| \\
& =\left\|N_{P}^{0-1} A_{2 P}\left(A_{1 P}^{0}-A_{1 P}\right) N_{P}^{-1} x\right\| \\
& \leq\left\|N_{P}^{0-1}\right\|\left\|A_{2 P}\right\|\left\|\left(A_{1 P}^{0}-A_{1 P}\right) N_{P}^{-1} x\right\| \\
& \leq a_{1}\left\|N_{P}^{0-1}\right\|\left\|A_{2 P}\right\|\left\|N_{P}^{-1} x\right\| \leq k a_{1}\left\|A_{2 P}\right\|\left\|N_{P}^{-1} x\right\| \\
& \leq k a_{1}\left\|A_{2 P}\right\|\left\|N_{P}^{-1}\right\|^{*}\|x\| \leq k a_{1} \varpi\left\|A_{2 P}\right\|\|x\| \leq \lambda\|x\|
\end{aligned}
$$

where $\lambda=k a_{1} \varpi\left\|A_{2 P}\right\|$ and $k=\left\|A_{2 P}\right\|\left(\mu_{A_{2 P}}+\mu_{A_{1 P}^{0}}\left\|A_{2 P}\right\|^{2}\right)^{-1}$. Let $w=u_{1}-A_{2 P} u_{2}$, then, for $u_{1}$ and $u_{2}$ in $B_{r}$, we have $\|w\|=\left\|u_{1}-A_{2 P} u_{2}\right\| \leq\left\|u_{1}\right\|+\left\|A_{2 P}\right\|\left\|u_{2}\right\| \leq\left(1+\left\|A_{2 P}\right\|\right) r$, so $w \in B_{\left(1+\left\|A_{2} P\right\|\right)}$, then

$$
\begin{aligned}
\left\|e_{1}-e_{1}^{0}\right\| & =\left\|\left(N_{P}^{-1}-N_{P}^{0-1}\right) w\right\| \\
& \leq \lambda\|w\| \leq \lambda\left\|u_{1}\right\|+\lambda\left\|A_{2 P}\right\|\left\|u_{2}\right\|
\end{aligned}
$$

and

$$
\begin{aligned}
e_{2}-e_{2}^{0} & =A_{1 P} N_{P}^{-1} w-A_{1 P}^{0} N_{P}^{0-1} w \\
& =A_{1 P} N^{-1} w-A_{1 P}^{0} N^{-1} w+A_{1 P}^{0} N^{-1} w-A_{1 P}^{0} N^{0-1} w
\end{aligned}
$$

from where

$$
\begin{aligned}
\left\|e_{2}-e_{2}^{0}\right\| & \leq\left\|\left(A_{1 P}-A_{1 P}^{0}\right) N^{-1} w\right\|+\left\|A_{1 P}^{0}\left(N^{-1} w-N^{0-1} w\right)\right\| \\
& \leq a_{1}\left\|N^{-1} w\right\|+\left\|A_{1 P}^{0}\right\|\left\|N^{-1} w-N^{0-1} w\right\| \\
& \leq a_{1} \varpi\|w\|+\lambda\left\|A_{1 P}^{0}\right\|\|w\| \\
& \leq\left(a_{1} \varpi+\lambda A_{1 P}^{0}\right)\left(\left\|u_{1}\right\|+\left\|A_{2 P}\right\|\left\|u_{2}\right\|\right)
\end{aligned}
$$

The third linearization result is:

Theorem 3.5. Let $A_{1}, A_{2}, A_{2}^{0}: H_{e} \mapsto H_{e}$ be the causal operators, where $A_{1}$ is linear, and be for all $P \in P, A_{1 P}, A_{2 P}$, the respective restrictions of $P A_{1}, P A_{2}$, to $H_{P}$. We assume that:

(a) $A_{1 P} \in \mathcal{M}$, with $\mu_{A_{1 P}}>0$ for any $P \in \mathcal{P}$, .

(b) $A_{2 P} \in$ Lip, with $\mu_{A_{2 P}} \leq 0$ for any $P \in \mathcal{P}$.

(c) There exist a causal and linear operator, $A_{2}^{0}: H_{e} \mapsto H_{e}, A_{2 P}^{0}$ and, there exists $a_{1} \geq 0$ such that, for all $x \in B_{\rho\left\|A_{1 P}\right\|\left(1+\mu_{A_{1 P}}^{-1}\right) r}$

$$
\left\|\left(A_{2 P}-A_{2 P}^{0}\right) x\right\| \leq a_{2}\|x\|,
$$


where for all $P \in \mathcal{P}, A_{2 P}^{0}$ is the restriction of $P A_{2}^{0}$ to $H_{P}, \mu_{A_{2 P}^{0}} \leq 0$ and

$$
\rho=\left\|A_{1 P}\right\|\left(\mu_{A_{1 P}}+\mu_{A_{2 P}}\left\|A_{1 P}\right\|^{2}\right)^{-1} .
$$

(d) $\mu_{A_{1 P}}+\left(\mu_{A_{2 P}}-a_{2}\right)\left\|A_{1 P}\right\|^{2}>0$. So

(i) The $F S^{\prime} s\left[A_{1}, A_{2}\right]$ and $\left[A_{1}, A_{2}^{0}\right]$ on $H_{e}$, are normal and Lipschitz continuous, for both inputs.

(ii) If $\left(u_{1}, u_{2}\right) \mapsto\left(e_{1}, e_{2}\right) \in H_{e}^{2} ;\left(u_{1}, u_{2}\right) \mapsto\left(e_{1}^{0} e_{2}^{0}\right) \in H_{e}^{2}$ where, $\left(u_{1}, u_{2}\right) \in H_{P}^{2}$ with $\left\|u_{1}\right\|,\left\|u_{2}\right\| \leq r$ and $\left(e_{1}, e_{2}\right),\left(e_{1}^{0}, e_{2}^{0}\right)$ the respective solutions of $\left[A_{1}, A_{2}\right]$ and $\left[A_{1}, A_{2}^{0}\right]$. Then

$$
\left\|e_{1}-e_{1}^{0}\right\| \leq \lambda\left\|u_{1}\right\|+\lambda \mu_{A_{1 P}}^{-1}\left\|u_{2}\right\|,
$$

and

$$
\left\|e_{2}-e_{2}^{0}\right\| \leq \lambda\left\|A_{1 P}\right\|\left\|u_{1}\right\|+\lambda \mu_{A_{1 P}}^{-1}\left\|A_{1 P}\right\|\left\|u_{2}\right\|,
$$

where

$$
\lambda=a_{2}\left\|A_{1 P}\right\|^{3}\left(\mu_{A_{1 P}}+\mu_{A_{2 P}}\left\|A_{1 P}\right\|^{2}\right)^{-1}\left(\mu_{A_{1 P}}+\mu_{A_{2 P}^{0}}\left\|A_{1 P}\right\|^{2}\right)^{-1} .
$$

\section{Proof}

(i) Let for all $x$ and $z$ in $H_{e}, M_{z} x=x+A_{2}\left(z+A_{1} x\right) ; M_{z}^{0} x=x+A_{2}^{0}\left(z+A_{1}^{0} x\right) ; B_{P z}=z+A_{1 P}$ and $B_{P z}^{0}=z+A_{1 P}^{0}$,.The operators $M_{z}$ and $M_{z}^{0}$ are causal; $M_{P z}=I+A_{2 P} B_{P z}$ and $M_{P z}^{0}=I+A_{2 P}^{0} B_{P z}$ are invertible (see lemme 4.3), threfore $M_{z}$ and $M_{z}^{0}$ are invertible (see lemma 4.4).

Since the operator $A_{2 P}^{0}$ is hemicontinuous, the $F S\left[A_{1}, A_{2}\right]$ and $\left[A_{1}, A_{2}^{0}\right]$ are normal.

Let's show that, $\left[A_{1}, A_{2}\right]$ is Lipschitz continuous for both inputs. We know that

$$
\begin{aligned}
& \left(e_{1}, e_{2}\right)=\left(M_{u_{2}}^{-1} u_{1}, u_{2}+A_{1} M_{u_{2}}^{-1} u_{1}\right) ; \\
& \left(e_{1}^{\prime}, e_{2}^{\prime}\right)=\left(M_{u_{2}}^{-1} u_{1}^{\prime}, u_{2}^{\prime}+A_{1} M_{u_{2}^{\prime}}^{-1} u_{1}^{\prime}\right) .
\end{aligned}
$$

Since, from lemma 4.4

$$
M_{u_{2}}^{-1} u_{1}=N^{-1}\left(u_{1}+A_{2}^{-1} u_{2}\right)-A_{2}^{-1} u_{2}
$$

we have

$$
\begin{aligned}
& P e_{1}=P N^{-1}\left(u_{1}+A_{1 P}^{-1} u_{2}\right)-P A_{1 P}^{-1} u_{2} ; \\
& P e_{1}^{\prime}=P N^{-1}\left(u_{1}^{\prime}+A_{1 P}^{-1} u_{2}^{\prime}\right)-P A_{1 P}^{-1} u_{2}^{\prime},
\end{aligned}
$$

and (see lemma 4.6)

$$
\begin{aligned}
\left\|P\left(e_{1}-e_{1}^{\prime}\right)\right\| \leq & \left\|P N_{P}^{-1}\left(u_{1}+A_{1 P}^{-1} u_{2}^{2}\right)-P N_{P}^{-1}\left(u_{1}^{\prime}+A_{1 P}^{-1} u_{2}^{\prime}\right)\right\| \\
& +\left\|A_{1 P}^{-1} P u_{2}^{\prime}-A_{1 P}^{-1} P u_{2}\right\| \\
\leq & \left\|N_{P}^{-1}\right\|^{*}\left(\left\|u_{1}-u_{1}^{\prime}\right\|+\left\|A_{1 P}^{-1}\right\|^{*}\left\|u_{2}-u_{2}^{\prime}\right\|\right) \\
& +\left\|A_{1 P}^{-1}\right\|^{*}\left\|u_{2}-u_{2}^{\prime}\right\| \\
\leq & \rho\left\|u_{1}-u_{1}^{\prime}\right\|+(1+\rho)\left\|A_{1 P}^{-1}\right\|^{*}\left\|u_{2}-u_{2}^{\prime}\right\|
\end{aligned}
$$

then,

$$
\begin{aligned}
\left\|e_{1}-e_{1}^{\prime}\right\| & \leq \rho\left\|u_{1}-u_{1}^{\prime}\right\|+(1+\rho)\left\|A_{1 P}^{-1}\right\|^{*}\left\|u_{2}-u_{2}^{\prime}\right\| \\
& \leq \lambda_{11}\left\|u_{1}-u_{1}^{\prime}\right\|+\lambda_{12}\left\|u_{2}-u_{2}^{\prime}\right\|
\end{aligned}
$$

with $\lambda_{11}=\rho$ and $\lambda_{12}=(1+\rho)\left\|A_{1 P}^{-1}\right\|^{*}$. 
On the other hand

$$
\begin{aligned}
e_{2} & =u_{2}+A_{1 P} M_{u_{2}}^{-1} u_{1} \\
& =u_{2}+A_{1 P}\left(N^{-1}\left(u_{1}+A_{1 P}^{-1} u_{2}\right)-A_{1 P}^{-1} u_{2}\right) ; \\
e_{2}^{\prime} & =u_{2}^{\prime}+A_{1 P}\left(N^{-1}\left(u_{1}^{\prime}+A_{1 P}^{-1} u_{2}^{\prime}\right)-A_{1 P}^{-1} u_{2}^{\prime}\right),
\end{aligned}
$$

therefore

$$
\begin{aligned}
& P e_{2}=P u_{2}+P A_{1 P}\left(N^{-1}\left(u_{1}+A_{1 P}^{-1} u_{2}\right)-A_{1 P}^{-1} u_{2}\right) ; \\
& P e_{2}^{\prime}=P u_{2}^{\prime}+P A_{1 P}\left(N^{-1}\left(u_{1}^{\prime}+A_{1 P}^{-1} u_{2}^{\prime}\right)-A_{1 P}^{-1} u_{2}^{\prime}\right),
\end{aligned}
$$

hence

$\left\|P\left(e_{2}-e_{2}^{\prime}\right)\right\|=$

$\left\|\left(P u_{2}-P u_{2}^{\prime}\right)+A_{1 P}\left(P N^{-1}\left(u_{1}+A_{1 P}^{-1} u_{2}\right)-A_{1 P}^{-1} u_{2}\right)-A_{1 P}\left(P N^{-1}\left(u_{1}^{\prime}+A_{1 P}^{-1} u_{2}^{\prime}\right)-A_{1 P}^{-1} u_{2}^{\prime}\right)\right\|$

$\leq\left\|u_{2}-u_{2}^{\prime}\right\|+\left\|A_{1 P}\right\|^{*}\left\|\left(N_{P}^{-1}\left(u_{1}+A_{1 P}^{-1} u_{2}\right)-A_{1 P}^{-1} u_{2}\right)-\left(N_{P}^{-1}\left(u_{1}^{\prime}+A_{1 P}^{-1} u_{2}^{\prime}\right)-A_{1 P}^{-1} u_{2}^{\prime}\right)\right\|$

$\leq\left\|u_{2}-u_{2}^{\prime}\right\|+\left\|A_{1 P}\right\|^{*}\left(\| N_{P}^{-1}\left(u_{1}+A_{1 P}^{-1} u_{2}\right)-N_{P}^{-1}\left(u_{1}^{\prime}+A_{1 P}^{-1} u_{2}^{\prime}\|+\| A_{1 P}^{-1} u_{2}-A_{1 P}^{-1} u_{2}^{\prime} \|\right)\right.$

$\leq\left\|u_{2}-u_{2}^{\prime}\right\|+\left\|A_{1 P}\right\|^{*}\left(\left\|N_{P}^{-1}\right\|^{*} \|\left(u_{1}+A_{1 P}^{-1} u_{2}\right)-\left(u_{1}^{\prime}+A_{1 P}^{-1} u_{2}^{\prime}\|+\| A_{1 P}^{-1} u_{2}-A_{1 P}^{-1} u_{2}^{\prime} \|\right)\right.$

$\leq\left\|u_{2}-u_{2}^{\prime}\right\|+\left\|A_{1 P}\right\|^{*}\left(\left\|N_{P}^{-1}\right\|^{*}\left\|u_{1}-u_{1}^{\prime}\right\|+\left\|N_{P}^{-1}\right\|^{*}\left\|A_{1 P}^{-1} u_{2}-A_{1 P}^{-1} u_{2}^{\prime}\right\|+\left\|A_{1 P}^{-1} u_{2}-A_{1 P}^{-1} u_{2}^{\prime}\right\|\right)$

$\leq\left\|u_{2}-u_{2}^{\prime}\right\|+\left\|A_{1 P}\right\|^{*}\left\|N_{P}^{-1}\right\|^{*}\left\|u_{1}-u_{1}^{\prime}\right\|+\left\|N_{P}^{-1}\right\|^{*}\left\|A_{1 P}\right\|^{*}\left\|A_{1 P}^{-1}\right\|^{*}\left\|u_{2}-u_{2}^{\prime}\right\|+\left\|A_{1 P}\right\|^{*}\left\|A_{1 P}^{-1}\right\|^{*}\left\|u_{2}-u_{2}^{\prime}\right\|$

$\leq \rho\left\|A_{1 P}\right\|^{*}\left\|u_{1}-u_{1}^{\prime}\right\|+\left(1+(\rho+1)\left\|A_{1 P}\right\|^{*}\left\|A_{1 P}^{-1}\right\|^{*}\right)\left\|u_{2}-u_{2}^{\prime}\right\|$

$=\lambda_{21}\left\|u_{1}-u_{1}^{\prime}\right\|+\lambda_{22}\left\|u_{2}-u_{2}^{\prime}\right\|$,

where $\lambda_{21}=\rho\left\|A_{1 P}\right\|^{*}$ and $\lambda_{22}=1+(\rho+1)\left\|A_{1 P}\right\|^{*}\left\|A_{1 P}^{-1}\right\|^{*}$. Therefore $\left[A_{1}, A_{2}\right]$ and $\left[A_{1}, A_{2}^{0}\right]$ are Lipschitz continuous for both inputs.

(ii) Let $\left(u_{1}, u_{2}\right) \mapsto\left(e_{1}, e_{2}\right) \in H_{e}^{2}$ and $\left(u_{1}, u_{2}\right) \mapsto\left(e_{1}^{0} e_{2}^{0}\right) \in H_{e}^{2}$, where $\left(u_{1}, u_{2}\right) \in H_{P}^{2}$ with $\left\|u_{1}\right\|,\left\|u_{2}\right\| \leq r$, and $\left(e_{1}, e_{2}\right),\left(e_{1}^{0}, e_{2}^{0}\right)$ the respective solutions of $\left[A_{1}, A_{2}\right]$ and $\left[A_{1}, A_{2}^{0}\right]$. Set $w=u_{1}+A_{1 P}^{-1} u_{2}$, then

$$
\begin{aligned}
\left\|A_{1 P} N^{-1} w\right\| & \leq\left\|A_{1 P}\right\| \rho\left(\left\|u_{1}\right\|+\mu_{A_{1 P}}^{-1}\left\|u_{2}\right\|\right) \\
& \leq\left\|A_{1 P}\right\| \rho\left(1+\mu_{A_{1 P}}^{-1}\right) r
\end{aligned}
$$

therefore, $A_{1 P} N^{-1} w \in B_{\left\|A_{1 P}\right\| \rho\left(1+\mu_{A_{1 P}}^{-1}\right) r}$. As

$$
\begin{aligned}
\left\|e_{1}-e_{1}^{0}\right\| & =\left\|M_{u_{2}}^{-1} u_{1}-M_{u_{2}}^{0-1} u_{1}\right\| \\
& =\left\|N^{-1}\left(u_{1}+A_{1 P}^{-1} u_{2}\right)-A_{1 P}^{-1} u_{2}-N^{0-1}\left(u_{1}+A_{1 P}^{-1} u_{2}\right)+A_{1 P}^{-1} u_{2}\right\| \\
& =\left\|\left(N^{-1}-N^{0-1}\right) w\right\| \\
& =\left\|N^{0-1}\left(N^{0}-N\right) N^{-1} w\right\| \\
& =\left\|N^{0-1}\left(A_{2 P}^{0} A_{1 P}-A_{2 P} A_{1 P}\right) N^{-1} w\right\| \\
& =\left\|N^{0-1}\left(A_{2 P}^{0}-A_{2 P}\right) A_{1 P} N^{-1} w\right\| \\
& \leq a_{2}\left\|N^{0-1}\right\|\left\|A_{1 P}\right\|\left\|N_{P}^{-1}\right\|^{*}\|w\| \\
& \leq \eta a_{2} \rho\left\|A_{1 P}\right\|\|w\| .
\end{aligned}
$$

We deduce that

$$
\left\|e_{1}-e_{1}^{0}\right\| \leq \lambda\|w\| \leq \lambda\left\|u_{1}\right\|+\lambda \mu_{A_{1 P}}^{-1}\left\|u_{2}\right\|
$$


where $w=u_{1}+A_{1 P}^{-1} u_{2}$ and $\lambda=\eta a_{2} \rho\left\|A_{1 P}\right\|$. On the other hand

$$
\begin{aligned}
\left\|e_{2}-e_{2}^{0}\right\| & =\left\|A_{1 P} M_{u_{2}}^{-1} u_{1}-A_{1 P} M_{u_{2}}^{0-1} u_{1}\right\|=\left\|A_{1 P}\left(N^{-1}-N^{0-1}\right) w\right\| \\
& \leq\left\|A_{1 P}\right\|\left\|N^{0-1}\left(N^{0}-N\right) N^{-1} w\right\| \\
& =\left\|A_{1 P}\right\|\left\|N^{0-1}\left(A_{2 P}^{0} A_{1 P}-A_{2 P} A_{1 P}\right) N^{-1} w\right\| \\
& \leq\left\|A_{1 P}\right\|\left\|N^{0-1}\left(A_{2 P}^{0}-A_{2 P}\right) A_{1 P} N^{-1} w\right\| \\
& \leq\left\|A_{1 P}\right\|\left\|N^{0-1}\right\|\left\|A_{2 P}^{0}-A_{2 P}\right\|\left\|A_{1 P}\right\|\left\|N_{P}^{-1}\right\|^{*}\|w\|,
\end{aligned}
$$

from where

$$
\begin{aligned}
\left\|e_{2}-e_{2}^{0}\right\| & \leq \lambda\left\|A_{1 P}\right\|\|w\| \\
& \leq \lambda\left\|A_{1 P}\right\|\left\|u_{1}\right\|+\lambda \mu_{A_{1 P}}^{-1}\left\|A_{1 P}\right\|\left\|u_{2}\right\| .
\end{aligned}
$$

\section{Conclusion}

(Vaclav Dolezal, 1979), introduced the notion of feedback systems in general, and established normality and linearization results on a Hilbert space. The notion of extended Hilbert space has also been introduced and one result of normality on this space has been demonstrated ( theorem 4.1). The importance of this theory and its fields of application is examined by the author in a series of publications of which the most interesting are cited in the references below. Considering the imprtance of extended spaces. In the present work, we have been interested, in the formulation and the establishment, of the results of normalities and linearizations, on this space.

\section{References}

Browder, F. E. (1968). Nonlinear maximal monotone operators in Banach space. Math annal, 175, 89-113. https://doi.org/10.1007/BF01418765

Brezis, H. (1968). Equations et inéquations non linéaires dans les espaces vectoriels en dualité. Ann. Inst. Fourier Grenoble, 18, 115-175. https://doi.org/10.5802/aif.280

Rockafellar, R. T. (1970). On lhe maximality of sums of nonlinear monotone operators. Trans. Amer. Math. Soc. May, 75-88. https://doi.org/10.1090/S0002-9947-1970-0282272-5

Vaclav, D. (1979). Feedback systems described by monotone operators. SIAM J. Control and Optimisation, 17(3), 339364. https://doi.org/10.1137/0317027

Vaclav, D. (1980). An approximation theorem for a Hammerstien-type equations and applications. SIAM J. Math. Anal., 11(2), 392-399.

Vaclav, D. (1990). Estimating the difference of operators inverses and sensitivity of systems. Nolinear Ana Th, MEApp, 15(10), 21-930.

Vaclav, D. (1991). Robust stability and sensitivity of input-output systems over extende spaces part 1, robust stability. Circuit, Systems and Signal Processing, 10(3), 361-389.

Vaclav, D. (1991). Robust stability and sensitivity of input-output systems over extende spaces part 2, robust stability. Circuit, Systems and Signal Processing, 10(4), 443-454.

Vaclav, D. (1995). Optimizaion of general nonlinear input-output systems. Nolinear Ana; Th, MEAApp, 24(4), 441-468. https://doi.org/10.1016/0362-546X(94)00100-V

Vaclav, D. (1998). Some results on the invertiblity of nonlinear operators. Circuit, Systems and Signal Processing, 17(6), 683-690. https://doi.org/10.1007/BF01206568

Vaclav, D. (1999). The invertiblity of operators and contraction mapping. Circuit, Systems and Signal Processing, 18(26), 183-187.

Vaclav, D. (2003) . Approximate inverses of operators. Circuit, Systems and Signal Processing, 22(1), 69-75. https://doi.org/10.1007/s00034-004-7014-4

Zames, G. (1963). Functional analysis applied to nonlinear feedback systems. IEEE Trans. Comm. Tech. CT, 10, 392-404. https://doi.org/10.1109/TCT.1963.1082162 


\section{Appendix}

This section is devoted to the reminders of the results of ((Vaclav Dolezal, 1979), corollary 1,2,3,5; lemma 6, 7, 8, 10 \& theorem 8) relating to our work.

Corollary 4.1. The $F S\left[A_{1}, A_{2}\right]$, where $A_{1}$ and $A_{2}$ are two operators on $H$, is normal if and only if $M_{a}$ is bijective, for all $a$ in $H$. In this case, for $\left(u_{1}, u_{2}\right)$ in $H^{2}$ the solution is given by

$$
\left(e_{1}, e_{2}\right)=\left(M_{u_{2}}^{-1} u_{1}, u_{2}+A_{1} M_{u_{2}}^{-1} u_{1}\right) .
$$

Corollary 4.2. Let $A_{1}$ and $A_{2}$ be two operators on $H$, of which $A_{2}$ is linear. $\left[A_{1}, A_{2}\right]$ is normal if the operator $I+A_{2} A_{1}$ is bijective. In this case, for $\left(u_{1}, u_{2}\right)$ in $H^{2}$ the solution is given by

$$
\begin{aligned}
& e_{1}=\left(I+A_{2} A_{1}\right)^{-1}\left(u_{1}-A_{2} u_{2}\right) ; \\
& e_{2}=u_{2}+A_{1}\left(I+A_{2} A_{1}\right)^{-1}\left(u_{1}-A_{2} u_{2}\right) .
\end{aligned}
$$

Lemma 4.1. Let $N \in M$, with $\mu_{N}>0$; if $N$ is hemicontinuous, then $N$ is invertible, $N^{-1} \in \operatorname{Lip}, \mu_{N^{-1}} \geq 0$ and $\left\|N^{-1}\right\|^{*} \leq \mu_{N}^{-1}$. If $N \in$ Lip then $\mu_{N^{-1}} \geq \mu_{N}\|N\|^{*-2}$.

Lemma 4.2. Let $A_{2} \in M$ be a hemicontinuous operator and $A_{1} \in$ Lip with $\mu_{A_{1}}>0$. If $\mu_{A_{2}}+\mu_{A_{1}}\left\|A_{1}\right\|^{*-2}>0$, then the operator $I+A_{2} A_{1}$ is invertible, $\left(I+A_{2} A_{1}\right)^{-1} \in$ Lip and

$$
\left\|\left(I+A_{2} A_{1}\right)^{-1}\right\|^{*} \leq \mu_{A_{1}}^{-1}\left(\mu_{A_{2}}+\mu_{A_{1}}\left\|A_{1}\right\|^{*-2}\right)^{-1} .
$$

If $A_{1}$ and $A_{2}$ are causal, $\left(I+A_{2} A_{1}\right)^{-1}$ is also causal.

Lemma 4.3. Let $A_{2} \in \mathcal{M}$ be a linear operator, such that $\mu_{A_{2}}>0$ and $A_{1} \in$ Lip a hemicontinuous operator with $\mu_{A_{1}} \leq 0$. If $\mu_{A_{2}}+\mu_{A_{1}}\left\|A_{2}\right\|^{2}>0$, then $I+A_{2} A_{1}$ is invertible, $\left(I+A_{2} A_{1}\right)^{-1} \in$ Lip and

$$
\left\|\left(I+A_{2} A_{1}\right)^{-1}\right\|^{*} \leq\left\|A_{1}\right\|\left(\mu_{A_{2}}+\mu_{A_{1}}\left\|A_{2}\right\|^{2}\right)^{-1} .
$$

If $A_{1}$ and $A_{2}$ are causal, $\left(I+A_{2} A_{1}\right)^{-1}$ is also causal.

Lemme 4.4. Let $A_{2} \in \mathcal{M}$ be hemicontinuous with $\mu_{A_{2}} \leq 0$ and $A_{1} \in \mathcal{M}$ a linear operator with $\mu_{A_{1}}>0$. If $\mu_{A_{1}}+\mu_{A_{2}}\left\|A_{1}\right\|^{2}>$ 0 , then $I+A_{2} A_{1}$ is invertible, $\left(I+A_{2} A_{1}\right)^{-1} \in$ Lip and

$$
\left\|\left(I+A_{2} A_{1}\right)^{-1}\right\|^{*} \leq\left\|A_{1}\right\|\left(\mu_{A_{1}}+\mu_{A_{2}}\left\|A_{1}\right\|^{2}\right)^{-1} .
$$

If, in addition de plus, $A_{1}$ and $A_{2}$ are causal, then $\left(I+A_{2} A_{1}\right)^{-1}$ is also causal.

Lemma 4.5. If $A_{1}, A_{2}: H_{e} \mapsto H_{e}$ are two operators, where $A_{1}$ is linear and invertible, and the operator $N=I+A_{2} A_{1}$ is invertible, then for the given $a$ in $H_{e}$, the operator $M_{a}=I+A_{2}\left(a+A_{1}\right)$ is invertible and the inverse $M_{a}^{-1}$ is given by:

$$
M_{a}^{-1} x=N^{-1}\left(x+A_{1}^{-1} a\right)-A_{1}^{-1} a, \forall x \in H_{e} .
$$

Lemma 4.6. Let $A: H_{e} \mapsto H_{e}$ be causal, and for every $P \in P, A_{p}: H_{P} \rightarrow H_{P}$ the restriction of $P A$ to $H_{P}$. Then $A$ is invertible and the inverse $A^{-1}: H_{e} \rightarrow H_{e}$ is causal iff $A_{p}$ is invertible for each $P \in P$. In that case

$$
P A^{-1}=A_{P}^{-1} P, \forall P \in \mathcal{P}
$$

and $A_{P}^{-1}$ is the restriction of $P A^{-1}$ to $H_{P}$

Théorème 4.1. Let $A_{1}, A_{2}: H_{e} \rightarrow H_{e}$ be tow causal operators. For all $P \in P, A_{1 P}$ and $A_{2 P}$ the restriction of $P A_{1}$ and $P A_{2}$ to $H_{P}$. Suppose that for each $P \in P$

(i) $A_{1 P} \in$ Lip and $\mu_{A_{1 P}}>0$;

(ii) $A_{2 P} \in M$ and it is hemicontinuous;

(iii) $\mu_{A_{2 P}}+\mu_{A_{1 P}}\left\|A_{1 P}\right\|^{*-2}>0$. 
Then, the $F S\left[A_{1}, A_{2}\right]$ over $H_{e}$ is normal and causal.

Moreover if, there exists $\lambda>0$ such that, for all $P \in P$

$$
\mu_{A_{1 P}}^{-1}\left(\mu_{A_{2 P}}+\mu_{A_{1 P}}\left\|A_{1 P}\right\|^{*-2}\right)^{-1} \leq \lambda,
$$

and, if $\left(u_{1}, u^{*}\right) \mapsto\left(e_{1}, e_{2}\right) \in H_{e}^{2} ;\left(u_{1}^{\prime} u^{*}\right) \mapsto\left(e_{1}^{\prime}, e_{2}^{\prime}\right) \in H_{e}^{2} ; u_{1-} u_{1}^{\prime} \in H$, then $e_{1-} e_{1}^{\prime} \in H$,

$$
\left\|e_{1-} e_{1}^{\prime}\right\| \leq \lambda\left\|u_{1-} u_{1}^{\prime}\right\| .
$$

If, in addition there existes $k>0$ such that, for all $P \in P,\left\|A_{1 P}\right\|^{*} \leq k$, also $e_{2-} e_{2}^{\prime} \in H$,

$$
\left\|e_{2}-e_{2}^{\prime}\right\| \leq \lambda k\left\|u_{1-} u_{1}^{\prime}\right\| .
$$

\section{Copyrights}

Copyright for this article is retained by the author(s), with first publication rights granted to the journal.

This is an open-access article distributed under the terms and conditions of the Creative Commons Attribution license (http://creativecommons.org/licenses/by/4.0/). 